\title{
Toward Detecting Infection Incidence in People With Type 1 Diabetes Using Self-Recorded Data (Part 1): A Novel Framework for a Personalized Digital Infectious Disease Detection System
}

Ashenafi Zebene Woldaregay ${ }^{1}$, MSc; Ilkka Kalervo Launonen ${ }^{2}$, PhD; Eirik Årsand ${ }^{1}$, PhD; David Albers ${ }^{3,4}$, PhD; Anna Holubová, ${ }^{5,6}, \mathrm{MSc}$; Gunnar Hartvigsen ${ }^{1}, \mathrm{PhD}$

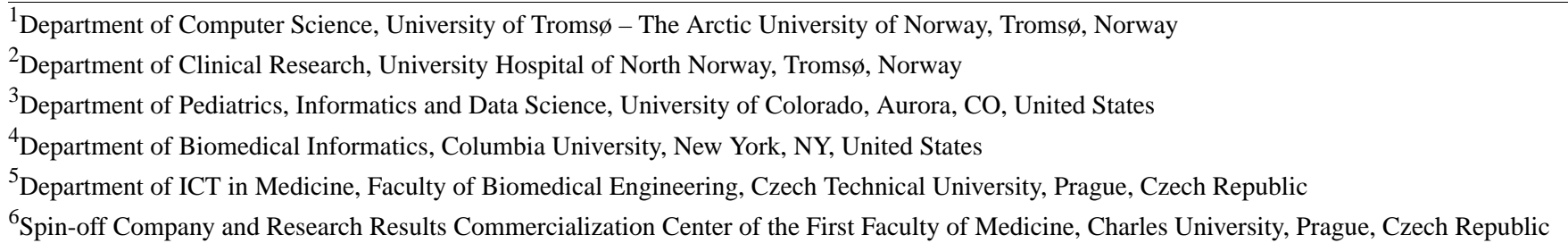

\section{Corresponding Author:}

Ashenafi Zebene Woldaregay, MSc

Department of Computer Science

University of Troms $\varnothing$ - The Arctic University of Norway

Hansine Hansens veg 54, Science building Realfagbygget, office A124

Troms $\varnothing$

Norway

Phone: 4746359333

Email: ashenafi.z.woldaregay@ uit.no

\section{Abstract}

Background: Type 1 diabetes is a chronic condition of blood glucose metabolic disorder caused by a lack of insulin secretion from pancreas cells. In people with type 1 diabetes, hyperglycemia often occurs upon infection incidences. Despite the fact that patients increasingly gather data about themselves, there are no solid findings that uncover the effect of infection incidences on key parameters of blood glucose dynamics to support the effort toward developing a digital infectious disease detection system.

Objective: The study aims to retrospectively analyze the effect of infection incidence and pinpoint optimal parameters that can effectively be used as input variables for developing an infection detection algorithm and to provide a general framework regarding how a digital infectious disease detection system can be designed and developed using self-recorded data from people with type 1 diabetes as a secondary source of information.

Methods: We retrospectively analyzed high precision self-recorded data of 10 patient-years captured within the longitudinal records of three people with type 1 diabetes. Obtaining such a rich and large data set from a large number of participants is extremely expensive and difficult to acquire, if not impossible. The data set incorporates blood glucose, insulin, carbohydrate, and self-reported events of infections. We investigated the temporal evolution and probability distribution of the key blood glucose parameters within a specified timeframe (weekly, daily, and hourly).

Results: Our analysis demonstrated that upon infection incidence, there is a dramatic shift in the operating point of the individual blood glucose dynamics in all the timeframes (weekly, daily, and hourly), which clearly violates the usual norm of blood glucose dynamics. During regular or normal situations, higher insulin and reduced carbohydrate intake usually results in lower blood glucose levels. However, in all infection cases as opposed to the regular or normal days, blood glucose levels were elevated for a prolonged period despite higher insulin and reduced carbohydrates intake. For instance, compared with the preinfection and postinfection weeks, on average, blood glucose levels were elevated by $6.1 \%$ and $16 \%$, insulin (bolus) was increased by $42 \%$ and $39.3 \%$, and carbohydrate consumption was reduced by $19 \%$ and $28.1 \%$, respectively.

Conclusions: We presented the effect of infection incidence on key parameters of blood glucose dynamics along with the necessary framework to exploit the information for realizing a digital infectious disease detection system. The results demonstrated that compared with regular or normal days, infection incidence substantially alters the norm of blood glucose dynamics, which are quite significant changes that could possibly be detected through personalized modeling, for example, prediction models and 
anomaly detection algorithms. Generally, we foresee that these findings can benefit the efforts toward building next generation digital infectious disease detection systems and provoke further thoughts in this challenging field.

(J Med Internet Res 2020;22(8):e18911) doi: 10.2196/18911

\section{KEYWORDS}

type 1 diabetes; self-recorded health data; infection incidence; decision making; infectious disease outbreaks; public health surveillance

\section{Introduction}

The incidence of infectious disease outbreaks can create panic in society and is a threat to local and global health security. Such outbreaks require immediate detection and appropriate response during the initial phase of the incidence to reduce fatality and save lives [1]. The timeliness of outbreak detection defines the success of the appropriate response by the concerned bodies. The state-of-the-art syndromic surveillance systems have been improved compared with the traditional surveillance system, which is generally passive and dependent on laboratory confirmation [2]. Syndromic surveillance makes use of features that come before diagnosis, including different activities triggered by the onset of symptoms, such as Google search, Twitter, school and work absenteeism, pharmacy drug sells, and other sources as a signal of change in individual and population health [2]. These signals are mainly acquired from the secondary source of information, typically built for other purposes. However, to keep up the pace with the rapidly changing social and biological dynamics, novel outbreak detection mechanisms are highly sought [2].

The advancement and omnipresence of smartphones, Internet of Things (IoT) devices, wearables, and sensors have enabled individuals to easily self-record health-related events often for self-tracking or self-managing their disease $[3,4]$. The recent movement known as quantified self and lifelogging is the result of such technological advancement, where people collect various kinds of health-related events and data for personal informatics purposes, that is, self-surveillance and self-management [5-8]. To this end, people with diabetes are not an exception, where they self-record detailed information as part of their self-management, including blood glucose levels, diet and insulin intake, physical activity, medication, and other information $[4,9,10]$. Consequently, a huge amount of self-recorded, personal health-related data is generated each day that have great potential to be used as a secondary source of information for other purposes such as digital epidemiology $[11,12]$. According to recent reports, personal health data or self-collected health-related data have provided an enormous opportunity to enhance the possibility of detecting infection incidence during the presymptomatic stage (improved sensitivity and timeliness), specifically during the incubation period, where most of the existing systems neglect from their process [13].

Type 1 diabetes is a chronic condition of blood glucose metabolic disorder caused by lack of insulin secretion from pancreas cells [14]. These patient groups are recommended to maintain their blood glucose levels within a specified range through self-management practice $[14,15]$. Blood glucose levels are controlled by balancing insulin and meal intake along with other contexts such as physical activity, medications, and others. Blood glucose dynamics are affected by various factors that can be categorized as common, individual, and unpredictable factors [16]. These factors could be further categorized as patient-controllable and patient-uncontrollable parameters [17]. Patient-controllable parameters incorporate factors on which the patient has direct control and can roughly understand their immediate effect on blood glucose dynamics. However, patient-uncontrollable parameters include factors in which the patient does not have direct control and faces a challenge to understand their immediate effect on blood glucose levels. From the patient perspective, usually patient-controllable parameters induce reasonable deviations on blood glucose levels; however, patient-uncontrollable parameters induce unreasonable blood glucose deviations and usually differ from the usual norm of blood glucose dynamics [18]. The total number of people living with diabetes is increasing worldwide. According to recent reports [14], there were 415 million people between the ages of 20 and 79 years in 2015, and this value is projected to increase by $54 \%$ in 2040 . From this figure, $5 \%$ are believed to have type 1 diabetes. In these patient groups, infection incidence often results in complications and difficulties in controlling blood glucose levels within the recommended range [19-21]. As a result, early detection of infection incidence among these patient groups could provide a way to assist the individual and at the same time can be used to realize a digital infectious disease detection system.

Currently, with the advancement of technology, the need to have a system that is able to detect infection incidence at the presymptomatic stage is highly sought [13]. In this regard, there are some previous investigations that have showcased the use of self-recorded data from people with diabetes as surveillance events (indicators) by uncovering the effect of infection incidence on blood glucose levels and glycemic control in real-life settings [18,22-36]. These studies reported the presence of prolonged hyperglycemia episodes as a result of infection incidence, thereby revealing the potential of self-recorded data as a secondary source of information for realizing a digital infectious disease detection system. For instance, Botsis et al [22] conducted a proof-of-concept study based on daily glycemic control data of 248 people with type 2 diabetes and concluded that blood glucose levels, insulin dosage, diet (carbohydrate consumption), physical activity, and other physiological parameters could be used as potential event indicators of infection incidence but calls for further investigations. Furthermore, Botsis et al [18] also reported elevated glycated hemoglobin $\left(\mathrm{HbA}_{1 \mathrm{c}}\right)$ levels after infections regardless of tight blood glucose control, which only settled down to normal levels after the patient recovered. Moreover, other studies conducted in hospital settings also reported similar results in this direction 
[37,38]. Despite reporting the potential of using self-recorded data as a surveillance event indicator, none of these studies demonstrated the extent to which each parameter is affected at an individual level as a result of infection incidence. Therefore, the purpose of this study was to retrospectively analyze the effect of infection incidence at an individual level and pinpoint optimal parameters that can effectively be used as input variables for developing an infection detection algorithm, thereby illustrating how these patient groups can assist in detecting infectious disease outbreaks. Moreover, this study provides a general framework regarding how a digital infectious disease detection system can be designed using self-recorded data from people with type 1 diabetes as a secondary source of information. Furthermore, this sheds light on the possibility of assisting the individual during such an incident. To this end, we analyzed temporal trends and probability distributions of different diabetes profile parameters (ie, blood glucose, insulin, carbohydrate, and others) to uncover the effect of infection incidence on the blood glucose dynamics, thereby identifying parameters that can effectively be used as potential events (indicators) of infection incidence. In addition, a framework is presented depicting the necessary structure to properly exploit self-recorded data from these patient groups to realize a real-time digital infectious disease detection system. This paper is structured as follows: the Methods section describes the materials and methods used to analyze the data sets. The Results section presents the results depicting the effect of acute infection incidence in comparison with regular or normal situations. The Discussion section presents the overall findings and proposes a framework for designing and developing a real-time digital infectious disease detection system using self-recorded data from these patient groups. The final section of Discussion presents our concluding remarks.

\section{Methods}

\section{Materials}

High precision self-recorded data of 10 patient years collected from 3 real subjects ( 2 males and 1 female) with type 1 diabetes were used. The patients were free from any other chronic or other form of disease, except the self-reported acute infection incidence throughout the entire data collection period. The data sets consisted of blood glucose measurements (self-monitoring of blood glucose [SMBG] and continuous glucose monitoring [CGM]), injected insulin (basal and bolus), diet (carbohydrate in grams), and self-reported events of acute infection. The patients used different diabetes self-management technologies throughout the data collection period to gather these data sets including the Diabetes Diary app (Norwegian Centre for E-health Research) [39], the Spike app [40], the xDrip with app, Dexcom CGM, insulin pens, and insulin pumps, as shown in Table 1 . The data sets consist of both normal years, without any significant acute infection incidence, and years with at least one or more acute infection incidence. The normal (without infection) patient years were used as a baseline to compare the effect of all patient-controllable parameters and patient-uncontrollable parameters against the self-reported incidence of acute infection. The self-reported incidences of acute infections were a case of influenza (flu) and mild and light common cold without fever. All the experiments and analyses were conducted using MATLAB version 2018a (Mathworks).

Table 1. Equipment used in diabetes self-management.

\begin{tabular}{|c|c|c|c|}
\hline \multirow[t]{2}{*}{ Patients } & \multicolumn{3}{|l|}{ Self-management } \\
\hline & $\mathrm{BG}^{\mathrm{a}}$ & Insulin administration & Diet \\
\hline Subject 1 & $\begin{array}{l}\mathrm{SMBG}^{\mathrm{b}} \text { — finger pricks recorded in the } \\
\text { Diabetes Diary mobile app and Dexcom } \\
\text { CGM }^{\mathrm{c}}\end{array}$ & $\begin{array}{l}\text { Insulin pen (multiple bolus and one-time basal in the } \\
\text { morning) recorded in the Diabetes Diary mobile app }\end{array}$ & $\begin{array}{l}\text { Carbohydrate in grams recorded in } \\
\text { the Diabetes Diary mobile app }\end{array}$ \\
\hline Subject 2 & $\begin{array}{l}\text { SMBG-finger pricks recorded in the } \\
\text { Spike mobile app and Dexcom G4 CGM }\end{array}$ & $\begin{array}{l}\text { Insulin pen (multiple bolus [Humalog] and one-time } \\
\text { basal [Toujeo] before bed) recorded in the Spike } \\
\text { mobile app }\end{array}$ & $\begin{array}{l}\text { Carbohydrate in grams recorded in } \\
\text { the Spike mobile app }\end{array}$ \\
\hline Subject 3 & $\begin{array}{l}\text { Enlite (Medtronic) CGM and Dexcom G4 } \\
\text { CGM }\end{array}$ & $\begin{array}{l}\text { Medtronic MinMed G640 insulin pump (basal rates } \\
\text { profile [Fiasp] and multiple bolus [Fiasp]) }\end{array}$ & $\begin{array}{l}\text { Carbohydrate in grams recorded in } \\
\text { pump information }\end{array}$ \\
\hline
\end{tabular}

${ }^{\mathrm{a}} \mathrm{BG}$ : blood glucose.

${ }^{\mathrm{b}} \mathrm{SMBG}$ : self-monitoring of blood glucose.

${ }^{\mathrm{c}} \mathrm{CGM}$ : continuous glucose monitoring.

\section{Patient Characteristics}

The participants were highly motivated individuals with type 1 diabetes who had advanced knowledge and understanding of several diabetes-related technologies. Hence, the self-recorded data can be regarded as highly precise and accurate. All the participants had advanced knowledge of carbohydrate counting, which can be considered as level 3 (advanced) [41]. The long-term average $\mathrm{HbA}_{1 \mathrm{c}}$ and characteristics of the participants are given in Table 2. 
Table 2. Participants characteristics.

\begin{tabular}{ll}
\hline Variables & Values \\
\hline Gender, $\mathbf{n}$ & 2 \\
Male & 1 \\
Female & $34(13.2)$ \\
Age (years), mean (SD) & \\
Body weight (kg) & 83 \\
Subject 1 & 77 \\
Subject 2 & 70 \\
Subject 3 & \\
HbA $\mathbf{1 c}$ (\%) & 6.0 \\
Subject 1 & 7.3 \\
Subject 2 & 6.2 \\
Subject 3 & Level 3 (advanced) \\
Carbohydrate counting & \\
\hline
\end{tabular}

${ }^{\mathrm{a}} \mathrm{HbA}_{1 \mathrm{c}}$ : glycated hemoglobin.

\section{Data Collection and Ethics}

The study protocol has been submitted to the Norwegian Regional Committees for Medical Health Research Ethics Northern Norway (REK) for evaluation and was found exempted from regional ethics review because it resides outside of the scope of medical research (reference number: 108435). Written consent was obtained and the participants donated the data sets. All data from the participants were anonymized.

\section{Approaches}

We retrospectively assessed and analyzed the diabetes profile (blood glucose, insulin, carbohydrate, and insulin-to-carbohydrate ratio) to uncover the nature, size, and shape of the infection-induced shift in the operating region of the blood glucose dynamics. A data size of 10 patient years incorporating blood glucose levels (SMBG and CGM), insulin (bolus and basal), diet (carbohydrate in grams), and self-reported events of acute infection was used. The analysis was performed based on specified timeframes (weekly, daily, and hourly) to reveal the effect of acute infection development on blood glucose dynamics. The data set incorporates 5 normal patient years without any infection incidence and 5 patient years each with at least one case of self-reported incidence of acute infection. Normal patient years were used as a baseline for comparison purposes. We analyzed the temporal evolution and probability distribution of blood glucose levels, injected insulin, carbohydrate intake (grams), and insulin-to-carbohydrate ratio within the stated timeframe. For the daily and hourly timeframes, a moving-average filter and nonparametric density estimation techniques, the kernel density estimator, were used to analyze the trend and data distribution before, during, and after the infection incidence. A moving-average filter with a window size of 2 days was employed to remove fast timescale features through smoothing. The window size includes $N-1$ observations from the previous data points and the current data point, where $N$ is the window size. Generally, the window size of a moving-average filter is determined based on complementary issues of better smoothing and the cost of significant delay (shift) incurred [42,43]. A small window size often generates less delay (shift) but at the cost of more short-term features and having a larger window size will smoothen the data in a better manner but at the cost of significant delay in the timeliness of detecting the infection incidence. Therefore, the window size was determined based on these complementary issues, and more importance was given to minimize the inherent delay (shift) incurred due to the window size. To this end, window sizes of $1,2,3$, and 4 days were applied and tested to choose the optimal size of the window, and as a result, a window size of 2 days was found to be satisfactory. The preinfection, infection, and postinfection week analyses were carried out on the raw data set based on the week's daily average and SD of blood glucose levels and daily sum and SD of insulin and carbohydrate. A statistical boxplot was used to depict the comparison during preinfection, infection, and postinfection weeks.

\section{Data Resampling, Imputation, and Preprocessing}

The features of the self-collected data from individuals with type 1 diabetes are shown in Table 3. The raw data were resampled at a uniform rate by assigning each measurement into the nearest time-bin based on its time stamp. Generally, whenever there is more than one measurement within each time-bin, the measurements are combined into a single measurement by either summing or averaging the elements. For blood glucose levels (both CGM and SMBG), the measurements were averaged into their respective sampling time-bins. However, regarding carbohydrate consumption and insulin injections, the sum of the elements in their respective sampling time-bin was computed, as shown in Table 4. In each time-bin, the effect of total insulin and total carbohydrate on the average blood glucose level was considered. The resampled data were further preprocessed using a moving-average filter with a 2-day (48-hour) window size to capture only the important patterns-long-term variation, while filtering and smoothing 
local and short-term variations. Moreover, for narrower time-bin resampling, for example, an hour, there are more frequent zeros of measurement, especially for carbohydrate and insulin measurements, which poses a significant challenge to compute the insulin-to-carbohydrate ratio as the ratio goes to infinity given that the carbohydrate amount is zero. Therefore, in such cases of a narrower time-bin, the ratio was computed only after computing the moving-average value of insulin and carbohydrate based on a window size of 48 hours. Regarding the missing blood glucose values during the hourly computations, a cubic spline interpolation was used to estimate the missing values.

Table 3. Self-collected user data.

\begin{tabular}{lll}
\hline Variable names & $\begin{array}{l}\text { Subject's record variables } \\
\text { Description }\end{array}$ & Units \\
\hline $\mathbb{U}^{c g}$ & Continuous glucose reading & $\mathrm{mg} / \mathrm{dL}$ \\
$\mathbb{U}^{g}$ & Self-management blood glucose reading & Units \\
$\mathbb{U}_{f}^{I}$ & Injected insulin (bolus) & Units \\
$\mathbb{U}_{s}^{I}$ & Injected insulin (basal) & Grams \\
$\mathbb{U}^{\mathbb{C}}$ & Ingested carbohydrate & \\
\hline
\end{tabular}


Table 4. Data preprocessing.

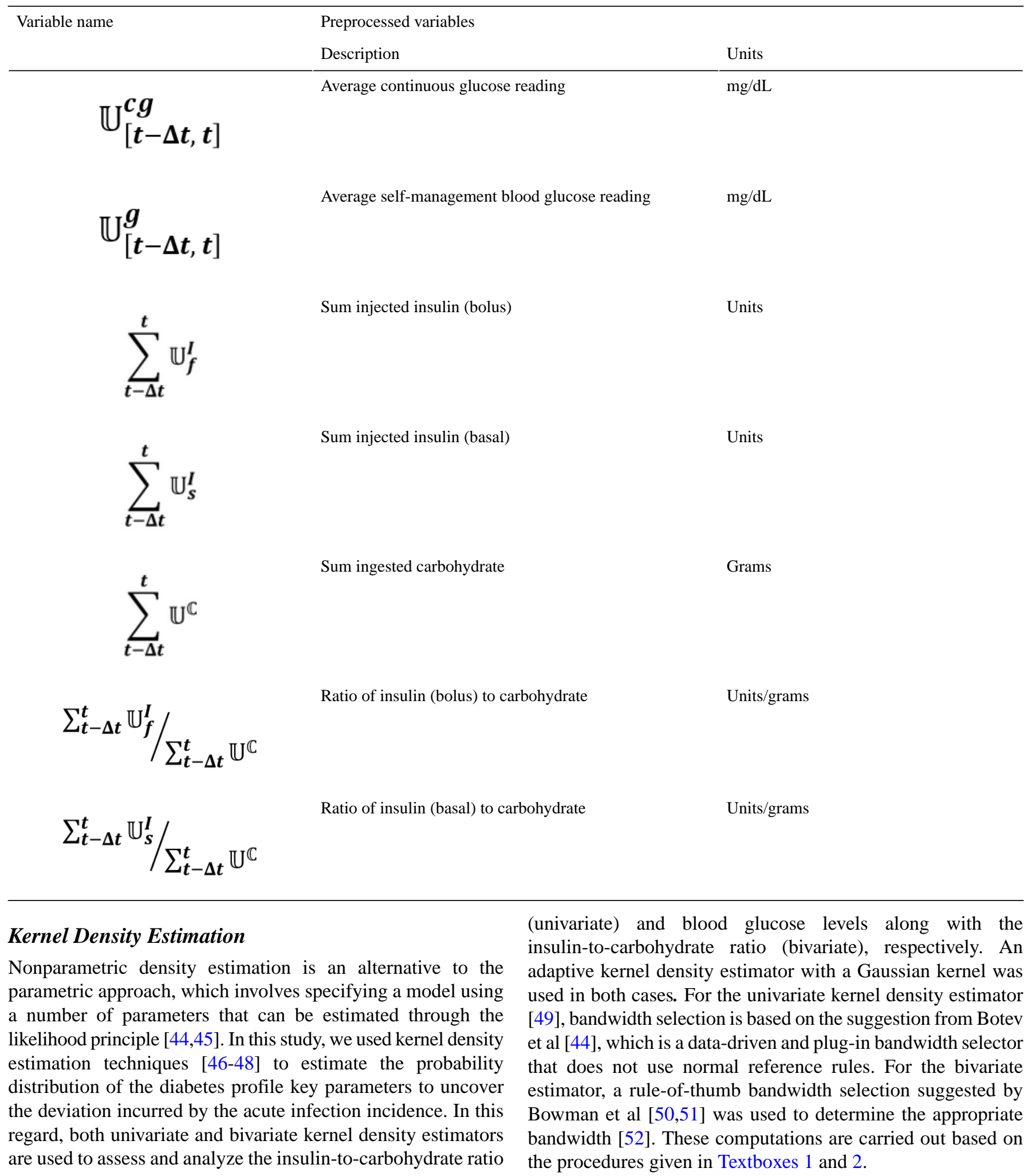

Textbox 1. One-dimensional adaptive kernel density estimation.

Approach: one-dimensional adaptive kernel density estimation

- Given: time series data sets of the insulin-to-carbohydrate ratio X $\varepsilon \mathrm{D}$ and an adaptive kernel density estimator $M$-one - dimensional

- Remove the reported days of infection from the time series data sets $\mathrm{D}$ and form a new data set $X \varepsilon \mathrm{Q}$

- Compute the one dimensional density based on the kernel density estimator $M$ using D and Q

- $\quad$ Compare the distribution from $M$ 
Textbox 2. Two-dimensional adaptive kernel density estimation.

Approach: two-dimensional adaptive kernel density estimation

- Given: time series data sets of blood glucose level and the insulin-to-carbohydrate ratio X, Y \& D and an adaptive kernel density estimator Ntwo - dimensional

- Remove the reported days of infection from the time series data sets $\mathrm{D}$ and form a new data set $X, Y \varepsilon \mathrm{Q}$

- Compute the two-dimensional density based on the kernel density estimator N using D and Q

- $\quad$ Compare the distribution from $\mathrm{N}$

\section{Results}

\section{Overview}

The analysis was conducted based on an hourly, daily, and weekly basis to reveal the deviations incurred due to the infection incidence. A total of 10 patient years were analyzed, and 5 of these years were found to include at least one incidence of acute infection lasting around 1-2 weeks. The proposed approach is designed to smooth out short-duration variations and include the 2 major patient-controllable factors, insulin and diet intake. Normal patient years were used to compare the effect of all patient-controllable parameters and patient-uncontrollable parameters against the self-reported incidence of acute infection. The trend analysis for both the normal patient years and patient years with acute infections using the proposed approach is presented below along with the nonparametric probability distribution. The weekly mean deviations of key diabetes parameters (blood glucose, insulin, and diet) during the preinfection, infection, and postinfection weeks are given in Multimedia Appendix 1.

\section{Trend Analysis}

\section{Trend Comparison for Normal Patient Years}

During normal years when patients do not have any significant illness or infections (Multimedia Appendix 2), the insulin-to-carbohydrate ratio follows a similar trend in all the subjects, where the insulin-to-carbohydrate ratio lies between 0.05 and 0.2. An elaborate analytical plot of a typical patient year without infection incidence showing the phenomena is depicted in Figures 1 and 2. A detailed analytical plot of the 5 patient years depicting the same phenomena can be found in Multimedia Appendix 2. The insulin-to-carbohydrate ratio conveys interesting information about the usual operating point of the patient, depicting the necessary amount of insulin (bolus) required for every gram of carbohydrate consumed to maintain the blood glucose levels within a healthy range (typically recommended to be between 70 and $180 \mathrm{mg} / \mathrm{dL}$ ). As can be seen from the yearlong trend analysis of the regular or normal patient years (Multimedia Appendix 2), despite the presence of various factors that are known to disturb blood glucose dynamics, both patient-controllable parameters and patient-uncontrollable parameters except infection incidence, the insulin-to-carbohydrate ratio remains to be relatively stable.

Figure 1. The first patient year, where there is no incidence of acute infections. The figure depicts the daily variation of average blood glucose levels, total insulin (bolus), total carbohydrate, and total insulin-to-total carbohydrate ratio. The operating point of the patient's insulin-to-carbohydrate ratio through these regular or normal days is between 0.05-0.2.
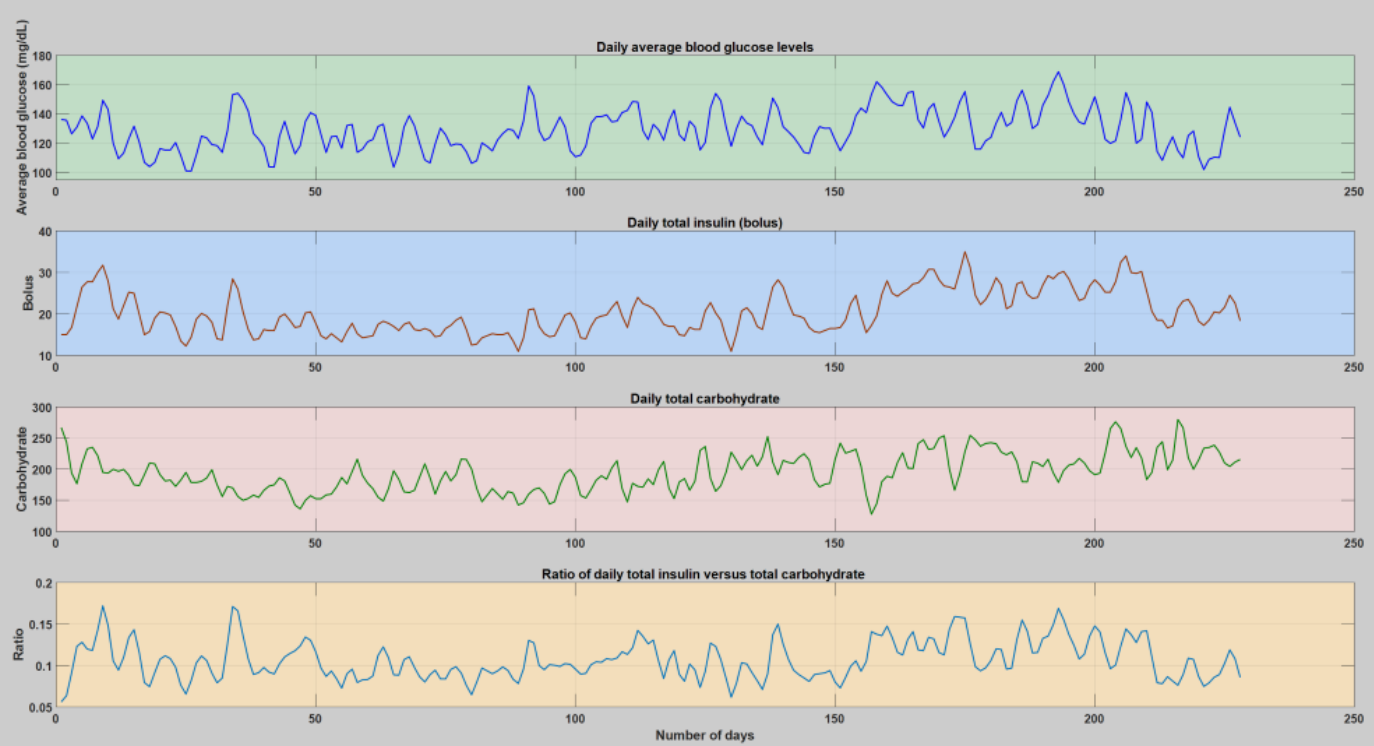
Figure 2. The first patient year, where there is no incidence of acute infections. The figure depicts variation of average blood glucose levels, total insulin (bolus), total carbohydrate, and total insulin-to-carbohydrate ratio during each hours of the day. The operating point of the patient's insulin-to-carbohydrate ratio through these regular or normal hours is between 0.05-0.2

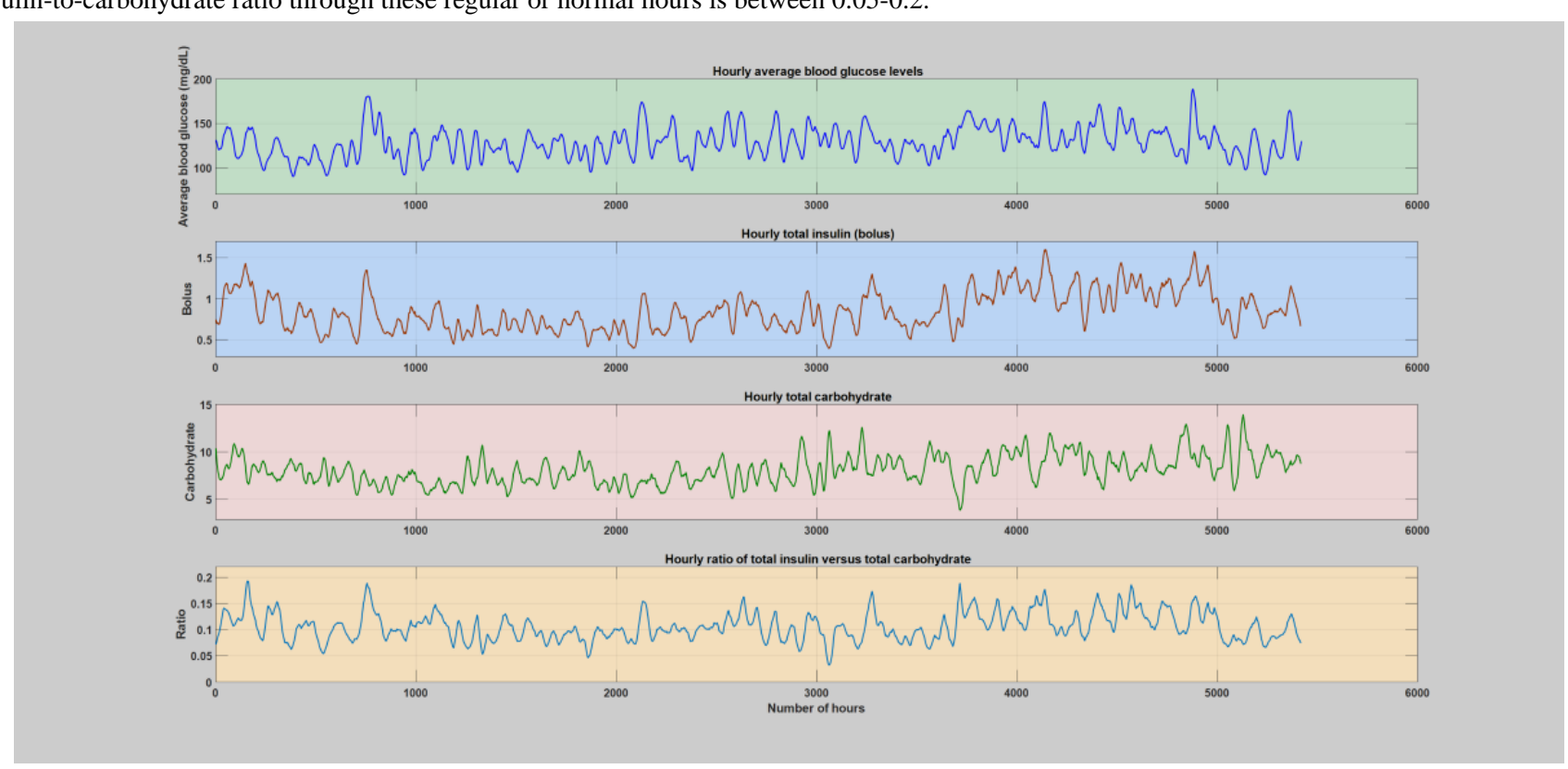

\section{Trend Comparison of Patient Years With Acute Infection}

The trend analysis of the key diabetes parameters, blood glucose, insulin, and carbohydrate, during acute infection suggests that there is a dramatic shift in the evolution of blood glucose, insulin, and carbohydrate (for detailed information, see Multimedia Appendices 1 and 3). Infection incidence brought about a dramatic increase in blood glucose levels, insulin intake, and reduction in carbohydrate consumption. The detailed analysis and the shift incurred on a weekly, daily, and hourly basis are presented in the following section.

\section{Weekly Analysis}

The weekly analysis of the patient years was conducted by analyzing the deviation incurred on the key parameters of the blood glucose dynamics during the infection week in comparison with before and after the infection incidence. The raw data were used to estimate the deviations incurred due to infection incidence. The mean and SD of blood glucose levels, total insulin (bolus), and total carbohydrate were computed and used for comparison of the infection-induced deviations. As shown in Figures 3-5 and Table 5, in all the infection cases, the weekly analysis demonstrated that blood glucose levels were elevated despite higher insulin injection and reduced carbohydrate consumption. In all of these cases, it is clear that the incidence of infection has brought unreasonable deviation, with respect to the patient-controllable parameters, in the operation of the overall blood glucose dynamics as compared with the usual norm of the blood glucose dynamics. The presence of elevated blood glucose levels in the infection week, regardless of the high amount of insulin injections and lower carbohydrate consumption, clearly violated the norm of the blood glucose dynamics, where during normal situations the blood glucose levels are expected to drop with high insulin and reduced carbohydrate consumption. The fact that the blood glucose remains elevated during the infection incidence despite higher insulin injections and low carbohydrate consumption is highly associated with the infection phenomenon, which enhances the production of glucose and increased insulin resistance within the body to deliver more energy for the body to fight the pathogens. A more detailed description of the weekly analysis can be found in Multimedia Appendix 1. 
Figure 3. Analysis of blood glucose levels during the preinfection week, infection week, and postinfection week based on the first case of infection (flu). The asterisk shows the mean value, and the red line depicts the median value for the week.

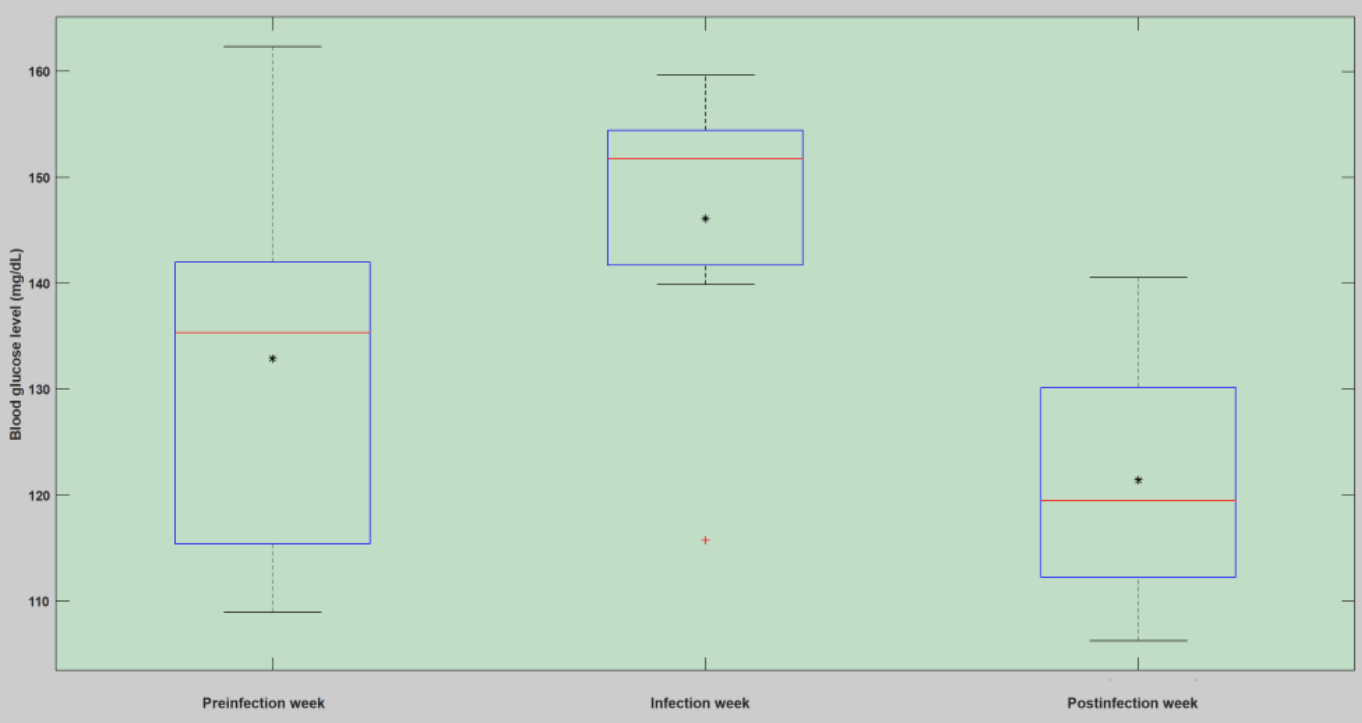

Figure 4. Analysis of total insulin (bolus) intake during preinfection week, infection week, and postinfection week based on the first case of infection (flu). The asterisk shows the mean value, and the red line depicts the median value for the week.

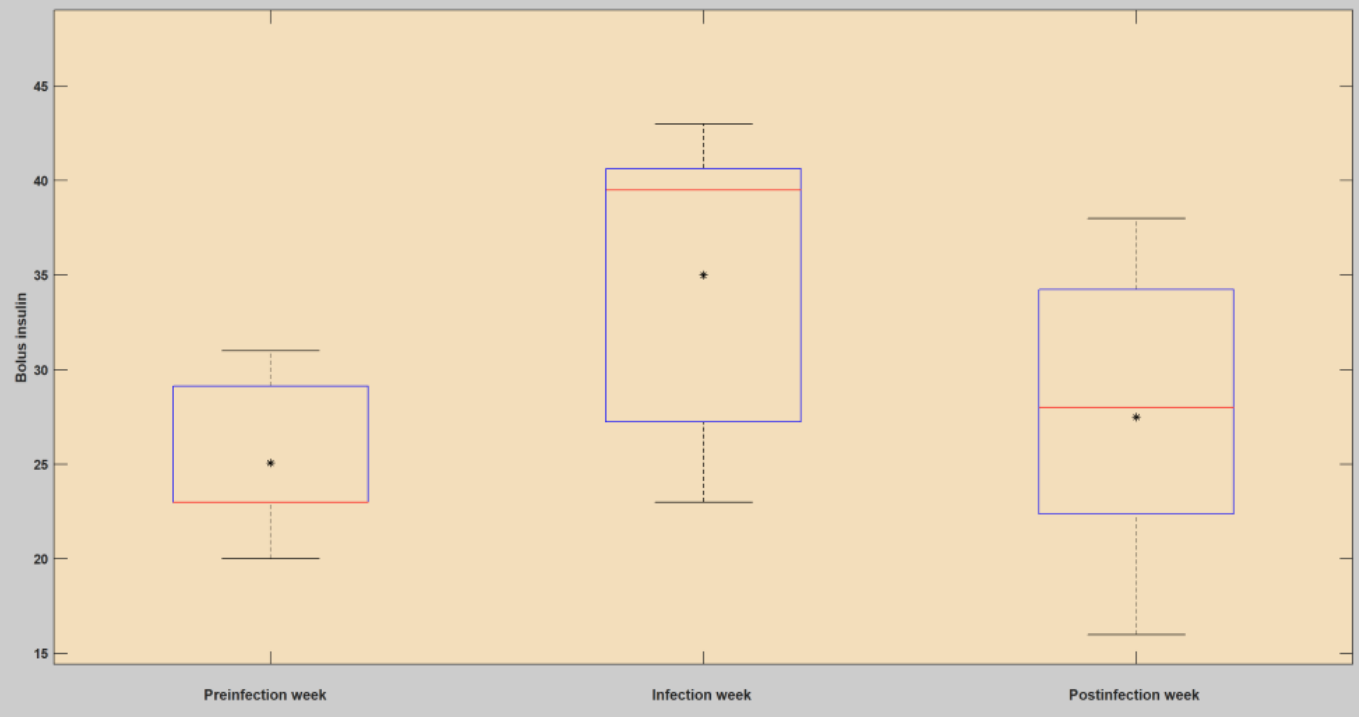


Figure 5. Analysis of total carbohydrate (grams) intake during preinfection week, infection week, and postinfection week based on the first case of infection (flu). The asterisk shows the mean value, and the red line depicts the median value for the week.

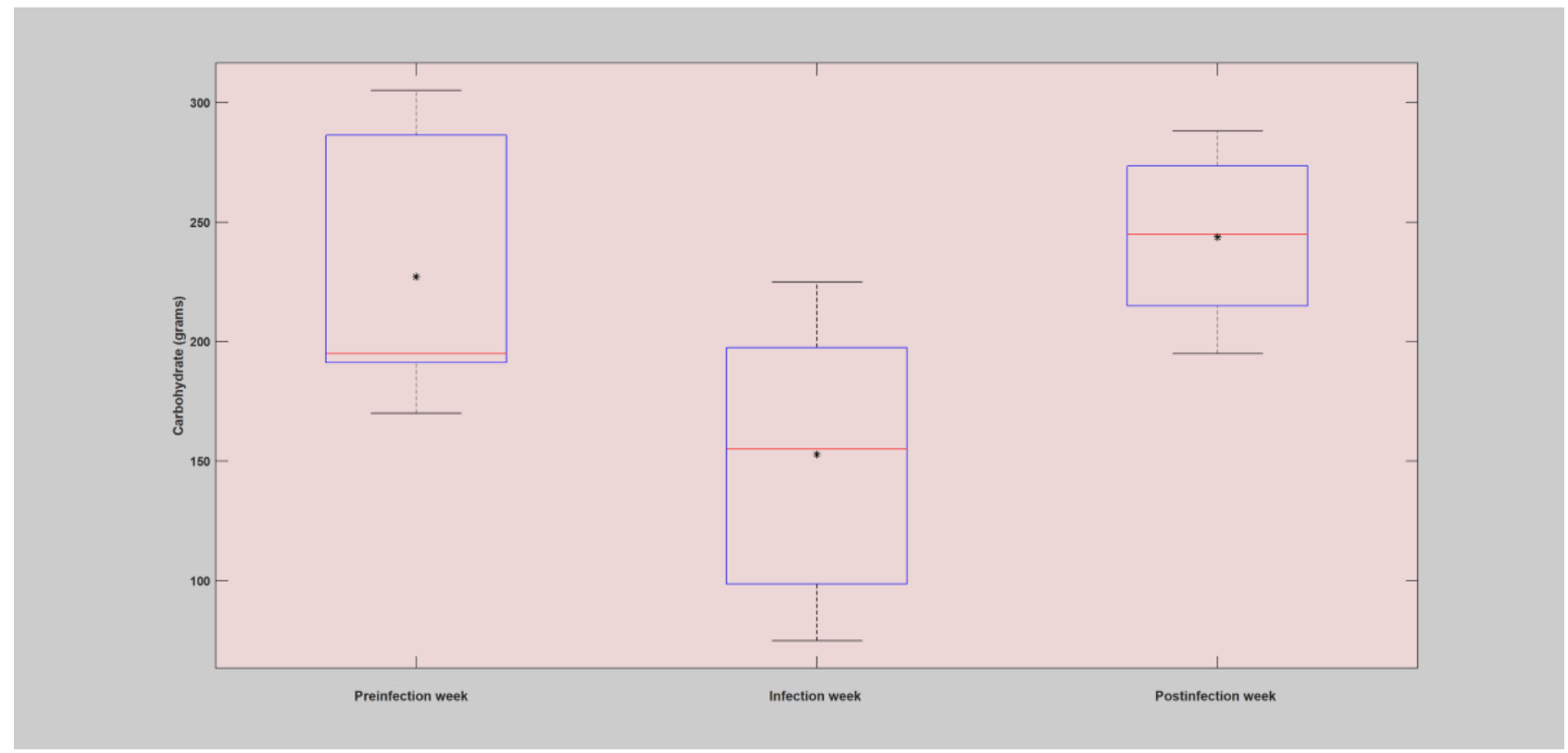

Table 5. Mean and standard deviation of blood glucose levels, total insulin (bolus), and total carbohydrate during the preinfection week, infection week, and postinfection week.

\begin{tabular}{|c|c|c|c|}
\hline Parameters & Preinfection week, mean (SD) & Infection week, mean (SD) & Postinfection week, mean (SD) \\
\hline \multicolumn{4}{|c|}{ The first case of infection (flu) } \\
\hline $\mathrm{BG}^{\mathrm{a}}(\mathrm{mg} / \mathrm{dL})$ & $130.74(16.89)$ & $141.95(14.37)$ & $119.16(7.39)$ \\
\hline Total insulin (bolus) & $23.39(4.91)$ & $35.30(6.11)$ & $21.32(4.61)$ \\
\hline Carbohydrate (grams) & $241.11(57.27)$ & $178.80(65.69)$ & $241.18(37.63)$ \\
\hline \multicolumn{4}{|c|}{ The second case of infection (flu) } \\
\hline $\mathrm{BG}(\mathrm{mg} / \mathrm{dL})$ & $143.01(19.53)$ & $155.36(21.99)$ & $126.17(11.70)$ \\
\hline Total insulin (bolus) & $28.07(8.85)$ & $41.07(9.44)$ & $25.36(6.93)$ \\
\hline Carbohydrate (grams) & $190.14(43.93)$ & $161.14(58.43)$ & $214.57(34.66)$ \\
\hline \multicolumn{4}{|c|}{ The third case of infection (flu) } \\
\hline $\mathrm{BG}(\mathrm{mg} / \mathrm{dL})$ & $136.93(18.58)$ & $144.12(20.30)$ & $134.18(11.96)$ \\
\hline Total insulin (bolus) & $20.08(5.44)$ & $31.50(10.84)$ & $22.83(3.86)$ \\
\hline Carbohydrate (grams) & $178.0(45.87)$ & $144.83(37.63)$ & $195.83(42.59)$ \\
\hline \multicolumn{4}{|c|}{ The fourth case of infection (flu) } \\
\hline $\mathrm{BG}(\mathrm{mg} / \mathrm{dL})$ & $157.74(31.12)$ & $161.34(19.88)$ & $138.57(19.83)$ \\
\hline Total insulin (bolus) & $24.43(5.26)$ & $32.14(7.01)$ & $29.29(5.22)$ \\
\hline Carbohydrate (grams) & $199.06(53.45)$ & $167.04(44.94)$ & $226.07(18.23)$ \\
\hline \multicolumn{4}{|c|}{ The fifth case of infection (flu) } \\
\hline $\mathrm{BG}(\mathrm{mg} / \mathrm{dL})$ & $135.21(14.58)$ & $139.88(15.54)$ & $122.87(14.49)$ \\
\hline Insulin (bolus) & $32.80(4.59)$ & $40.37(8.31)$ & $33.36(7.94)$ \\
\hline Insulin (basal) & $19.20(1.21)$ & $20.42(2.06)$ & $18.68(1.56)$ \\
\hline Total insulin & $52.33(5.14)$ & $61.21(8.26)$ & $52.46(8.47)$ \\
\hline
\end{tabular}

${ }^{\mathrm{a}} \mathrm{BG}$ : blood glucose. 


\section{Blood Glucose Levels}

In all these infection incidences, the individual blood glucose levels remain elevated for a prolonged period of time despite low carbohydrate consumption and increased insulin injections as compared with the regular or normal days. Blood glucose levels were elevated during the infection week as compared with the preinfection and postinfection weeks.

- During the first case of infection, the overall mean percentage increase in the infection week's blood glucose levels was $8.57 \%$ over the preinfection week and $19.12 \%$ over the postinfection week, as shown in Table 5.

- During the second case of infection, the overall mean percentage increase in the infection week's blood glucose levels was $8.63 \%$ over the preinfection week and $23.13 \%$ over the postinfection week, as shown in Table 5.

- During the third case of infection, the overall mean percentage increase in the infection week's blood glucose levels was $7.26 \%$ over the preinfection week and $7.41 \%$ over the postinfection week, as shown in Table 5.

- During the fourth case of infection, the overall mean percentage increase in the infection week's blood glucose levels was $2.28 \%$ over the preinfection week and $16.43 \%$ over the postinfection week, as shown in Table 5.

- During the fifth case of infection, the overall mean percentage increase in the infection week's blood glucose levels was $3.45 \%$ over the preinfection week and $13.84 \%$ over the postinfection week, as shown in Table 5.

\section{Insulin Intake}

The comparison of infection week insulin injections with preinfection and postinfection weeks revealed that there was a dramatic increase in the amount of insulin intake during the infection period.

- During the first case of infection, the overall mean percentage increase in the infection week's insulin (bolus) injection was $50.93 \%$ over the preinfection week and $65.59 \%$ over the postinfection week, as shown in Table 5.

- During the second case of infection, the overall mean percentage increase in the infection week's insulin (bolus) injection was $46.31 \%$ over the preinfection week and $61.94 \%$ over the postinfection week, as shown in Table 5.

- During the third case of infection, the overall mean percentage increase in the infection week's insulin (bolus) injection was $56.87 \%$ over the preinfection week and $37.98 \%$ over the postinfection week, as shown in Table 5.

- During the fourth case of infection, the overall mean percentage increase in the infection week's insulin (bolus) injection was $31.56 \%$ over the preinfection week and $9.7 \%$ over the postinfection week, as shown in Table 5.

- During the fifth case of infection, the overall mean percentage increase in the infection week's insulin (bolus) injection was $23.08 \%$ over the preinfection week and $21.01 \%$ over the postinfection week, as shown in Table 5.

\section{Carbohydrate Consumption}

Comparison of the amount of carbohydrate consumption during the infection week with the preinfection and postinfection weeks revealed that there was a significant reduction during the infection period.

- During the first case of infection, the overall mean percentage reduction in the infection week's carbohydrate consumption was $25.84 \%$ below the preinfection week and $25.87 \%$ below the postinfection week, as shown in Table 5.

- During the second case of infection, the overall mean percentage reduction in the infection week's carbohydrate consumption was $15.25 \%$ below the preinfection week and $24.90 \%$ below the postinfection week, as shown in Table 5.

- During the third case of infection, the overall mean percentage increase in the infection week's carbohydrate consumption was $18.63 \%$ below the preinfection week and $26.04 \%$ below the postinfection week, as shown in Table 5.

- During the fourth case of infection, the overall mean percentage increase in the infection week's carbohydrate consumption was $16.09 \%$ below the preinfection week and $35.34 \%$ below the postinfection week, as shown in Table 5.

\section{Insulin-to-Carbohydrate Ratio}

The insulin-to-carbohydrate ratio defines the amount of insulin a patient needs to take for every gram of carbohydrate consumed. The value of the insulin-to-carbohydrate ratio usually lies between 0.05 and 0.2 on normal occasions. However, it has dramatically increased upon the incidence of infection.

- During the first case of infection, the overall mean percentage increase in the infection week's insulin-to-carbohydrate ratio was around $125.84 \%$ above the normal operating point of the patient, as shown in Table 5 .

- During the second case of infection, the overall mean percentage increase in the infection week's insulin-to-carbohydrate ratio was approximately $144.43 \%$ above the normal operating point of the patient, as shown in Table 5.

- During the first case of infection, the overall mean percentage increase in the infection week's insulin-to-carbohydrate ratio was around $93.75 \%$ above the normal operating point of the patient, as shown in Table 5.

- During the fourth case of infection, the overall mean percentage increase in the infection week's insulin-to-carbohydrate ratio was approximately $70.84 \%$ above the normal operating point of the patient, as shown in Table 5.

\section{Daily and Hourly Analysis}

Hourly and daily analyses were conducted by analyzing the deviations incurred on the key diabetes parameters, blood glucose levels, insulin, carbohydrate, and the insulin-to-carbohydrate ratio as a result of infection incidence in contrast to the whole patient year. The comparison was carried out based on the smoothed version of the data, that is, 2 days window moving-average filter. Similar to the weekly analysis, the infection-induced shift of the blood glucose dynamics, that 
is, higher glucose production and increased insulin resistance, is clearly shown in both the daily and hourly analyses. As can be seen in Figures 6-11, the insulin-to-carbohydrate ratio of the patient has drastically shifted to a higher value to account for the effect of increased glucose production and insulin resistance (see Multimedia Appendix 3 for a detailed plot of the hourly analysis in all the infection cases). In all of these cases, the insulin-to-carbohydrate ratio increases from the usual values of 0.05 to 0.2 during the normal period to higher values reaching 0.6 , depending on the degree of severity of the infection incidence, type of pathogens involved, and the individual immunity.

Figure 6. Daily analysis of the first infection case (flu). The figure depicts variation of average blood glucose levels, total insulin (bolus), total carbohydrate, and total insulin-to-total carbohydrate ratio. The operating point of the patient's insulin-to-carbohydrate ratio had dramatically shifted and raised above the regular or normal days and reach a top around 0.5 upon midinfection week.
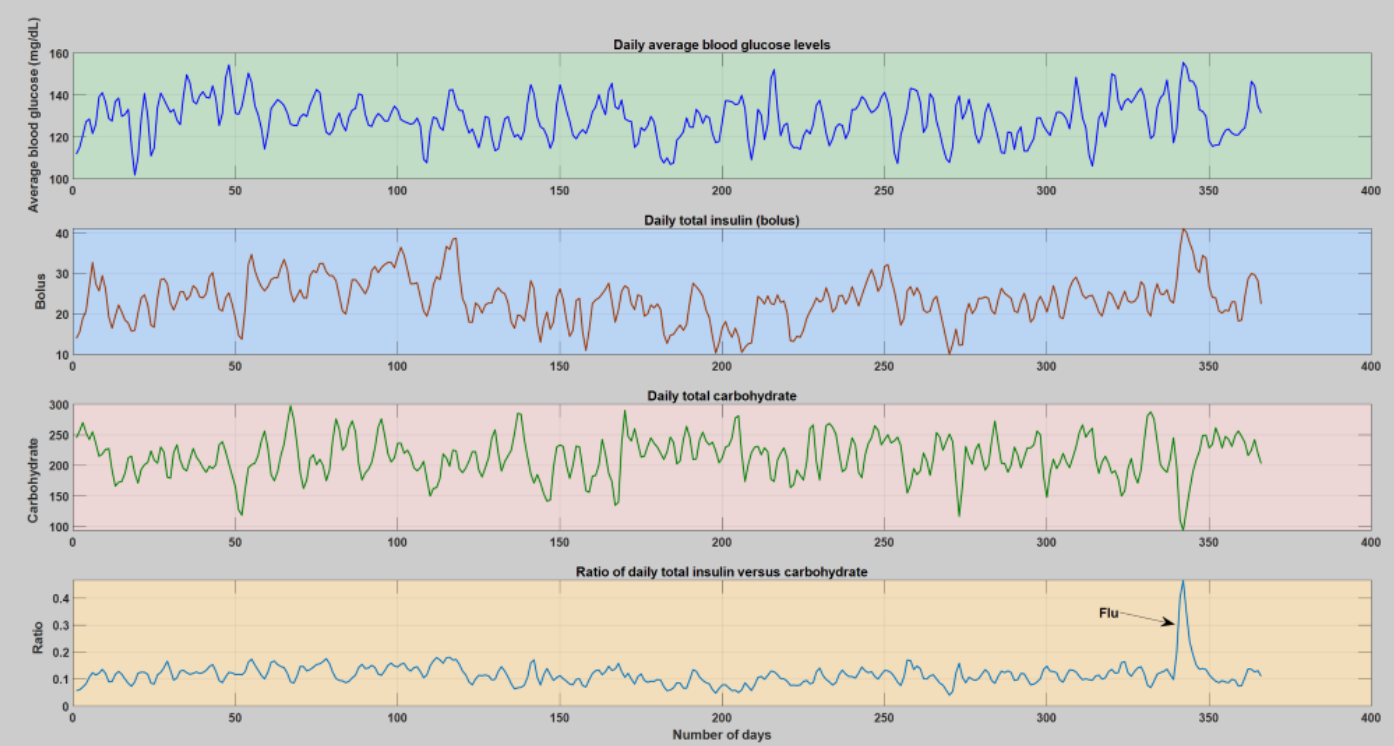

Figure 7. Hourly analysis of the first infection case (flu). The figure depicts variation of average blood glucose levels, total insulin (bolus), total carbohydrate, and total insulin-to-total carbohydrate ratio. The operating point of the patient's insulin-to-carbohydrate ratio had dramatically shifted and raised above the regular or normal days and reach a top around 0.5 upon midinfection week.
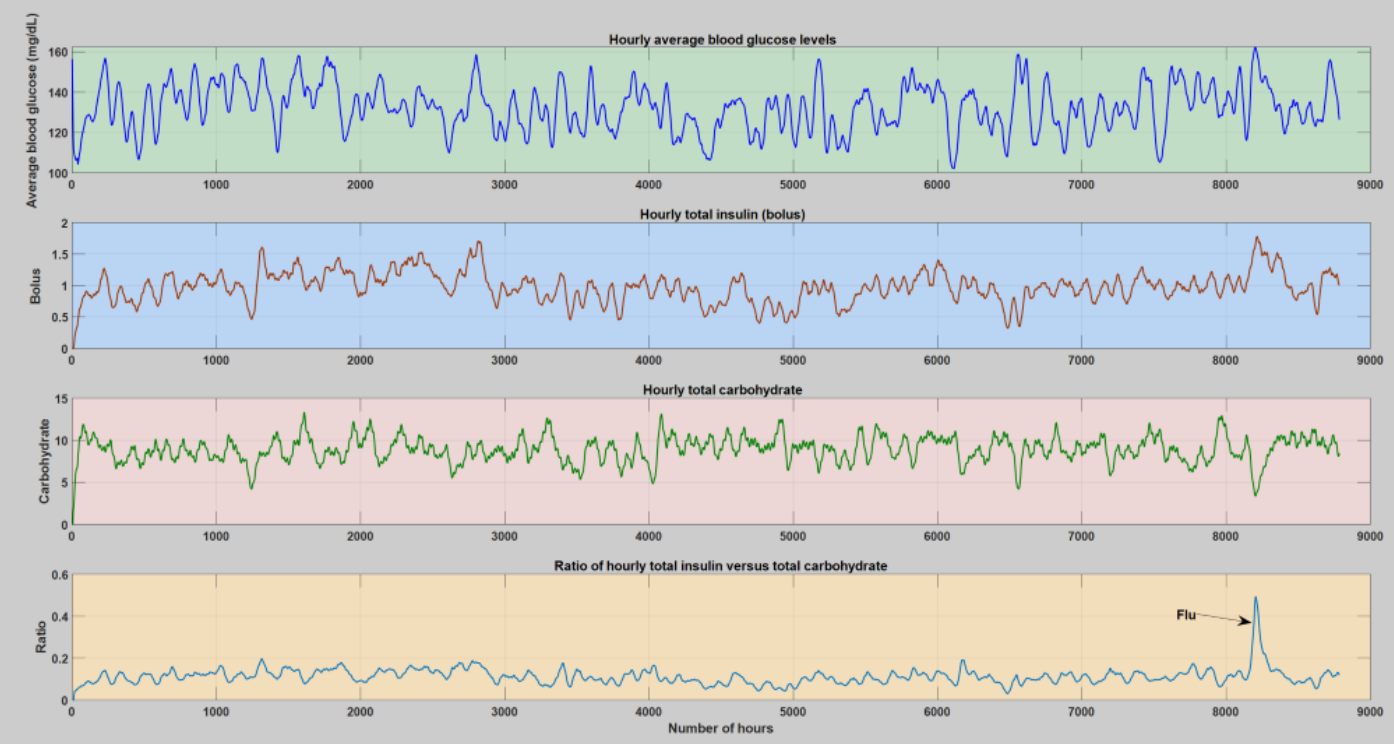
Figure 8. Daily analysis of the second infection case (flu). The figure depicts variation of average blood glucose levels, total insulin (bolus), total carbohydrate, and total insulin-to-total carbohydrate ratio. The operating point of the patient's insulin-to-carbohydrate ratio had dramatically shifted and raised above the regular or normal days and reach a top around 0.45 upon midinfection week.
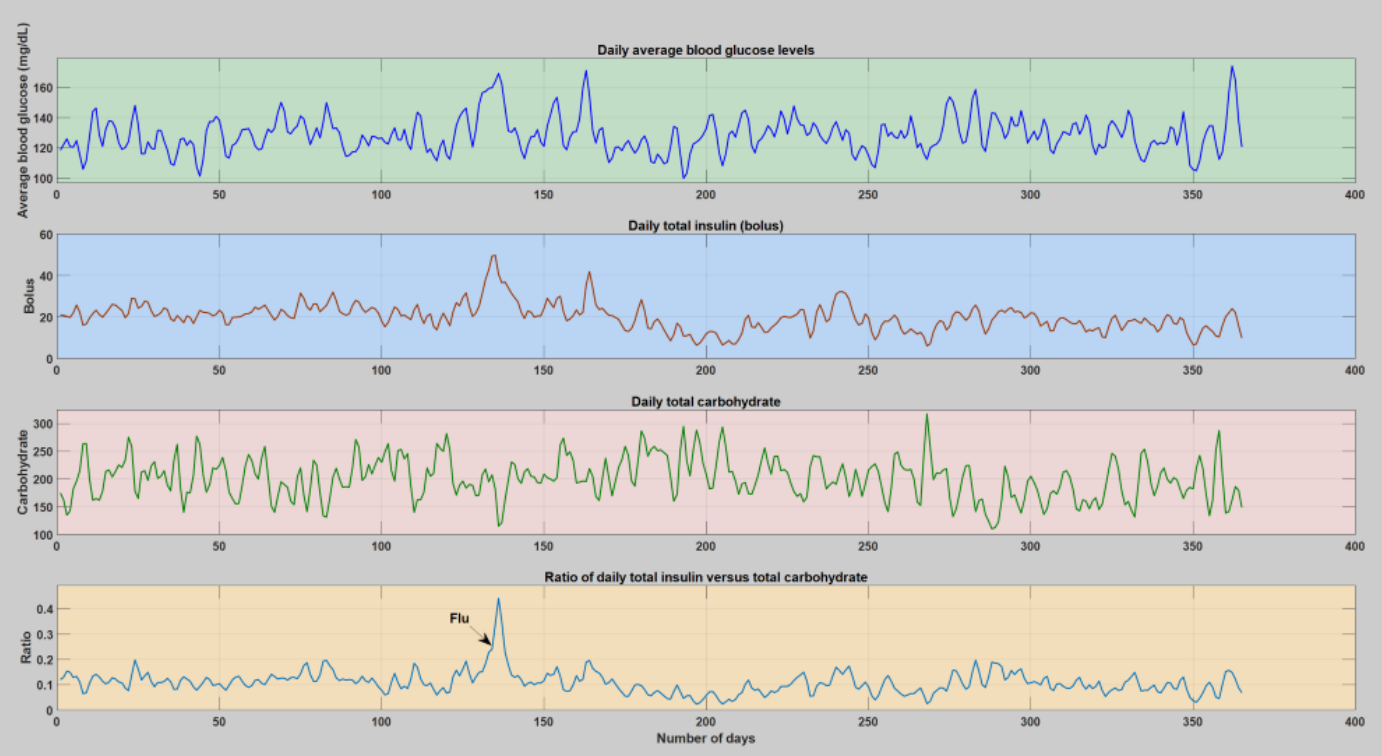

Figure 9. Daily analysis of the third infection case (flu). The figure depicts variation of average blood glucose levels, total insulin (bolus), total carbohydrate, and total insulin-to-total carbohydrate ratio. The operating point of the patient's insulin-to-carbohydrate ratio had dramatically shifted and raised above the regular or normal days and topped around 0.4 upon midinfection week.
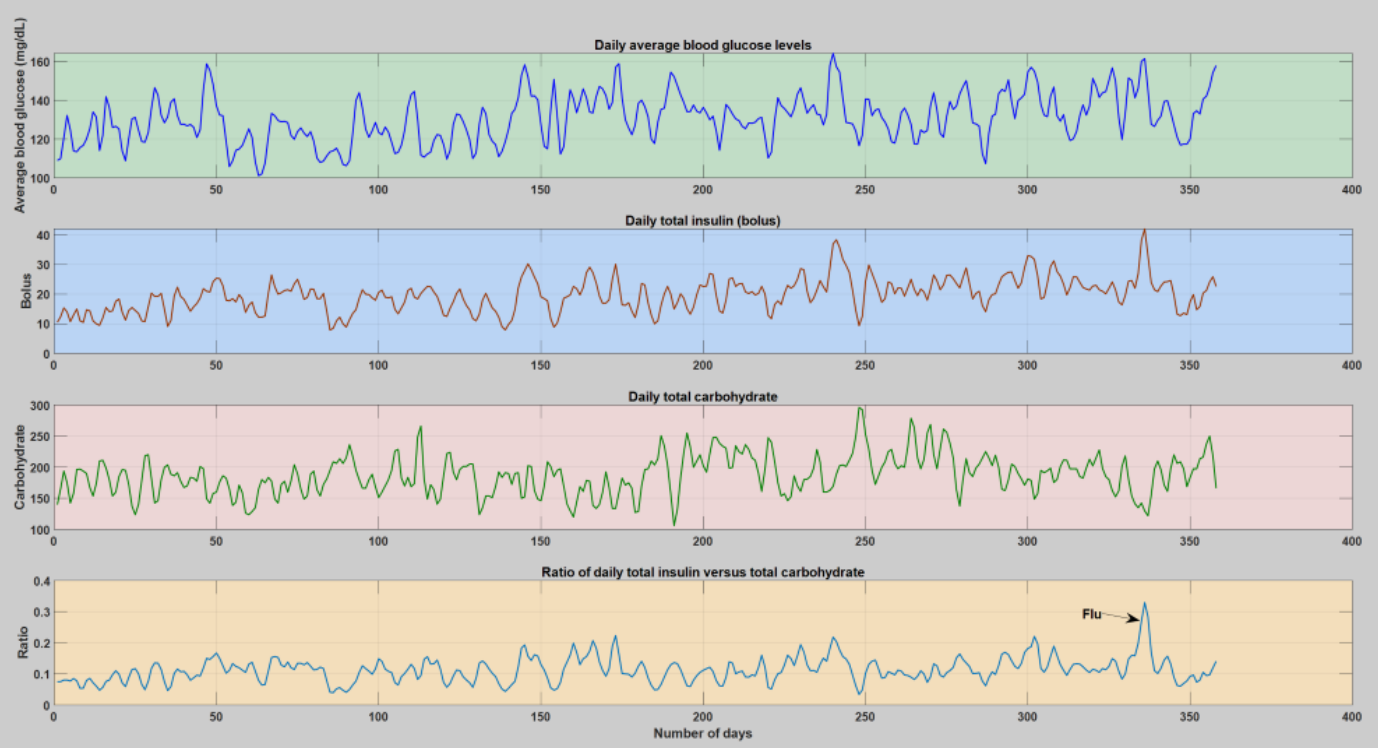
Figure 10. Daily analysis of the fourth infection case (mild common cold without fever, light common cold without fever, and flu). The figure depicts variation of average blood glucose levels, total insulin (bolus), total carbohydrate, and total insulin-to-total carbohydrate ratio. The operating point of the patient's insulin-to-carbohydrate ratio had dramatically shifted and raised above the regular or normal days and reach a top around 0.28 upon midinfection week. A light common cold without fever seems to not significantly affect the operating point.

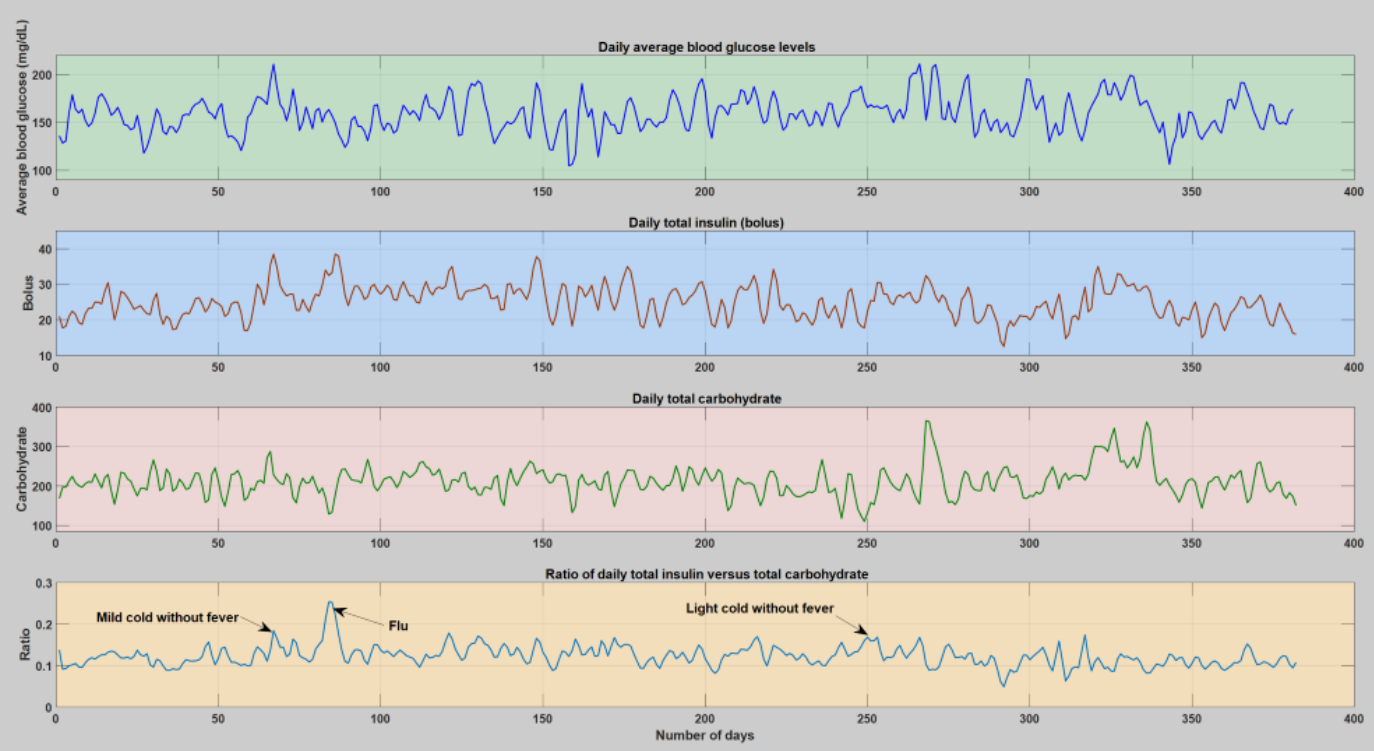

Figure 11. Daily analysis of the fifth infection case (flu). The figure depicts variation of average blood glucose levels, total insulin including both bolus and basal insulin, daily average rate of change of CGM and, absolute value of rate of change of CGM (computed based on CGM direction from the pump information), percentage of basal and bolus per total insulin units. As can be seen, as a result of the ongoing infection incidence, there is clear and dramatic rise in the amount of insulin, while blood glucose levels remain elevated.
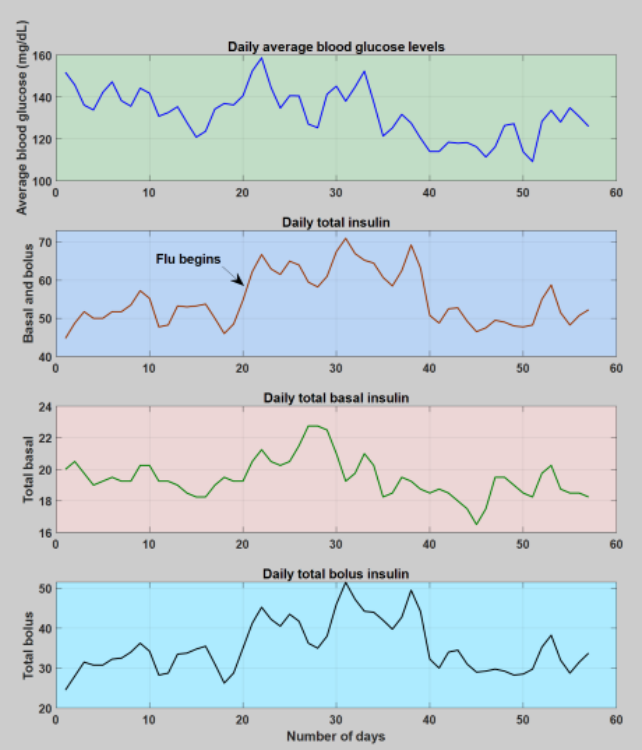

\section{Kernel Density Estimation-Probability Distribution}

Kernel density was estimated to study and characterize the nature, shape, and degree of severity of the deviations incurred due to infection incidence by analyzing the probability distribution of the individual key parameters of the blood glucose dynamics. A univariate and bivariate kernel density estimation based on the insulin-to-carbohydrate ratio and blood
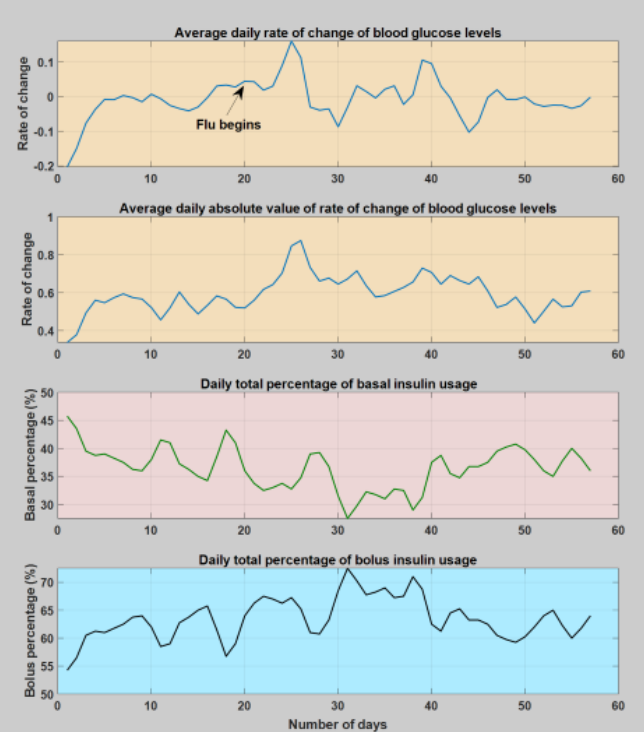

glucose levels was carried out on the yearlong data, as shown in Figures 12 and 13 (a detailed plot for all the infection cases, both hourly and daily, can be found in Multimedia Appendix 1). As can be seen from the figures, the infection incidence has brought a significant change in the probability distribution. However, the nature, shape, and degree of outlierness depend on the type of pathogen involved, severity of infection, and individual immunity. 
Figure 12. Univariate kernel density estimation of a patient year using the daily insulin-to-carbohydrate ratio. As can be seen from the tail of the distribution, during regular or normal days (the green shaded region), the yearly distribution of the patient's insulin-to-carbohydrate ratio lies within the values of 0.005 and 0.2 . However, during infection incidence (the red shaded region), there is a clear deviation in the tail of the distribution, where the values reaches around 0.58 .
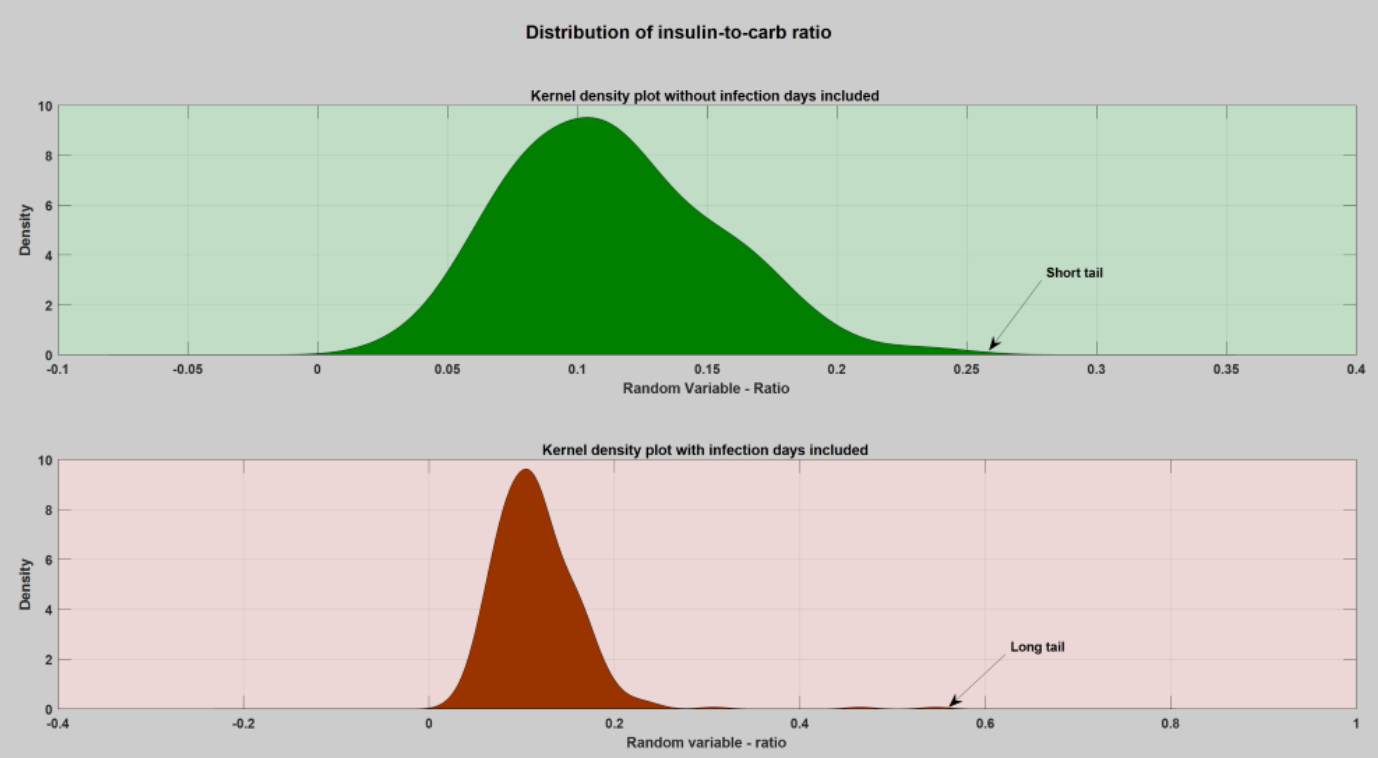

Figure 13. Bivariate kernel density estimation of a patient year using both the daily average blood glucose levels and insulin-to-carbohydrate ratio. As can be seen from the bivariate distribution, during regular or normal days (the top light green figure), the distributions are concentrated around the high density regions. However, during infection incidence (the lower figure), there is a clear bump far from the high density regions.
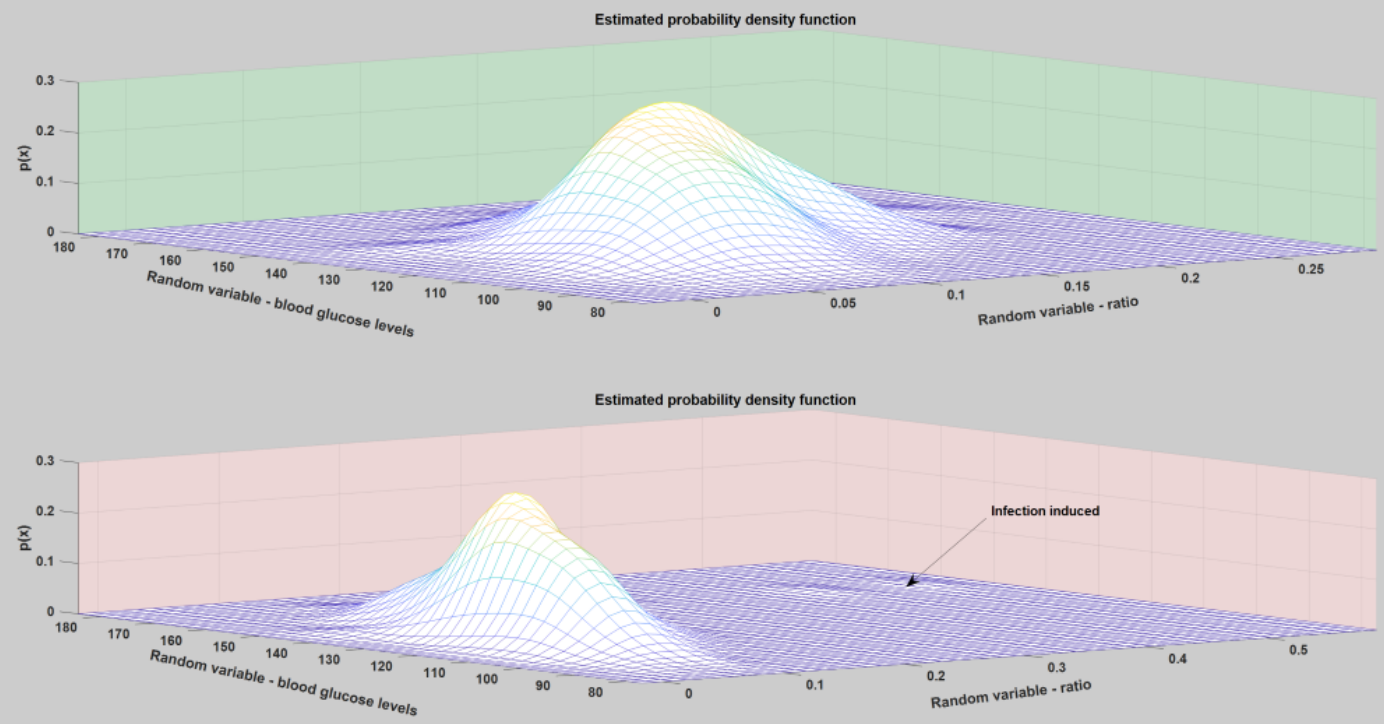

\section{Discussion}

\section{Principal Findings}

Presently, in relation to people's mobility and travel, there is a growing concern regarding an infectious disease outbreak. Such an incident can be a menace to our global health security, which calls for early detection and immediate response. Thus, there is a growing need for new approaches and technologies to upgrade the existing surveillance system for early detection of emerging infectious diseases [1]. Existing disease surveillance systems detect the incidence of outbreaks long after the incidence of the first symptoms. Therefore, the purpose of this study was to demonstrate how people with type 1 diabetes can assist in outbreak detection and further to shed light upon the possibility of assisting the individual during such an incident.

The advancement and omnipresence of smartphones, IoT devices, wearables, and sensors have enabled individuals to easily self-record health-related events often for self-tracking or self-managing their disease $[5,6,53]$. People with diabetes self-record detailed information including blood glucose levels, diet and insulin intake, physical activity, medication, and other parameters. The presence of such large self-recorded health data presents an opportunity to be used as a secondary source of information for other purposes such as digital epidemiology 
and decision support applications. According to recent reports, the use of personal health information or self-collected data could mitigate the possibility of detecting infection incidence during the presymptomatic stage (improved sensitivity and timeliness), specifically during the incubation period, of which most of the current systems neglect from their process [13]. Our findings demonstrated that upon infection incidence, there is a dramatic shift in the operating point of the individual's blood glucose dynamics, which clearly violates the usual norm of blood glucose dynamics. During regular or normal days, blood glucose levels usually decrease when there is a significant increase in insulin injection and reduction in carbohydrate consumption. However, in all of the infection cases we analyzed, compared with the preinfection and postinfection weeks, the following were noticed:

- Blood glucose levels were elevated by an average of $6.1 \%$ and $16 \%$ over the preinfection and postinfection weeks, respectively.

- Insulin injection (bolus) increased by $42 \%$ and $39.3 \%$ over preinfection and postinfection weeks, respectively.

- Carbohydrate consumption was reduced by $19 \%$ and $28.1 \%$ compared with preinfection and postinfection weeks, respectively.

- The insulin-to-carbohydrate ratio increased by $108.7 \%$ on average in all cases.

In general, all of these findings confirm that during infection incidence, blood glucose levels are elevated despite injecting higher amounts of insulin and reduced carbohydrate consumption. The identified changes are quite significant anomalies compared with the regular or normal days and could potentially be detected with a dedicated personalized (individualized) computational health model. Various algorithms that span from prediction models to anomaly detection algorithms can be investigated to detect such infection-induced changes in blood glucose dynamics. Apart from the potential use of these findings in personalized digital infectious disease detection systems, it could also be used for decision support in self-management during infection and illness. As presented earlier, during the course of infection, individuals with diabetes usually struggle with severe hyperglycemia. Managing blood glucose levels during infection incidence is not an easy task, given the fact that it is caused by a mixed effect of both patient-controllable and patient-uncontrollable parameters. The patient can only estimate the disturbance caused by the amount of carbohydrate consumption, insulin injection, and physical activity load, which is not the case during infection incidence. Apart from these known major factors, that is, patient-controllable parameters, there is an underlying and unknown disturbance caused by the patient's uncontrollable parameters, such as counterregulatory hormones (CRHs), as a result of infection incidence. This unknown disturbance mainly increases glucose production from the liver and reduces insulin sensitivity. To this end, people with type 1 diabetes face a very difficult challenge to estimate the necessary amount of insulin for a given amount of carbohydrate consumption. In this regard, providing real-time decision support could reduce the burden during such a crisis. One possible approach could be characterizing the effect of different pathogens on blood glucose dynamics, mainly on insulin resistance and its sensitivity change over the course of infection. However, a large set of infection-related self-recorded data need to be analyzed for investigating how each pathogen affects the key parameters of blood glucose dynamics during the entire course of infection. This requires collecting and analyzing infection-related data, and estimating the overall changes each pathogen could bring on insulin sensitivity during the course of infection. To this end, the presented result reflects a promising result that can be geared toward decision support during infection or illness. For example, the change in insulin-to-carbohydrate ratio can be used to provide general information related to each pathogen on what to expect, such as the percentage of insulin resistance during the first days, in the middle, and at the final days of the infection.

\section{Infection-Induced Shift of Operating Point in Blood Glucose Dynamics}

During infection incidence, people with diabetes usually struggle with severe hyperglycemia and critical hypoglycemia if not properly managed. However, during regular or normal days, the patient can manage the incidence of hyperglycemia, which is mostly diet-induced, by properly controlling the patient-controllable parameters, for example, amount of carbohydrate consumption, insulin injection, and performing balanced physical activity or exercise. Yet, during infection incidence, it turns out to be very difficult to manage the hyperglycemia incidence due to the fact that it is caused by a mixed effect of both patient-controllable and patient-uncontrollable parameters. The patient's uncontrollable parameters define the action of hormonal effects such as CRH induced by either physiological stress or emotional stress. The hormonal effect is two-sided, which is a higher glucose production from the liver and inhibiting insulin production and reducing sensitivity [54,55]. A detailed study conducted by Waldhausl et al [56] demonstrated the significant effect of stress hormones on the production of glucose and insulin resistance. The study was conducted by infusing different stress hormones to investigate the effect of exposure to these hormones on blood glucose response [55]. The extent and degree of hyperglycemia events and insulin resistance during infection incidence directly correlate with the type of pathogen, the type of hormone involved and the severity of the infection $[37,38,55]$. Generally, the phenomenal effect of infection incidence on blood glucose dynamics in people with diabetes can be simply described using the following relationships:

$$
\mathrm{BG}_{t}=\mathrm{CH}_{t}+\mathrm{CRH}_{t}-\varphi \mathrm{IN}_{t}-\mathrm{PA}_{t}
$$

Where $\phi$ is an insulin sensitivity factor, BG is the blood glucose level, $\mathrm{CH}$ is the amount of carbohydrate consumption, IN is the amount of insulin injection, PA is the amount of physical activity session or exercise load, and CRH is the effect of CRHs. The equation depicts the phenomena that occur during infection incidence, where blood glucose levels are raised by the action of both patient-controllable parameters $(\mathrm{CH})$ and patient-uncontrollable parameters (CRHs, such as cortisol and adrenalin). Thus, consumption of any regular diet in an individual can induce severe hyperglycemia due to the added effect of glucose production from the liver as a result of the 
CRH effect [55]. For this reason, the patient is expected to reduce the amount of carbohydrate intake to a certain extent to optimally manage the hyperglycemia crises and at the same time avoiding any critical hypoglycemia incidences (for more information, see Multimedia Appendix 1). By the same token, blood glucose levels can be lowered to euglycemia by the patient-controllable parameters (insulin [IN] and physical activity session or exercise load [PA]). However, due to the change in insulin sensitivity, the action of insulin is reduced ( $\phi$ is affected by infection incidence), and the patient is expected to deliver more insulin injections to counterbalance the effect of insulin resistance [57]. According to our results, all these scenarios are reflected in the individual's blood glucose dynamic infected with flu (influenza), where a dynamic shift occurred from the usual operating point of the blood glucose dynamics. There are elevated blood glucose levels, despite injecting a higher amount of insulin and consuming less carbohydrate than the regular or normal days. These characteristics are clearly demonstrated on the shift incurred on the individual's insulin-to-carbohydrate ratio as compared with the regular or normal days. Therefore, blood glucose, amount of injected insulin, diet intake, and insulin-to-carbohydrate ratio and other supporting physiological parameters such as body temperature and blood pressure can be exploited to develop a personalized health model for detecting infection incidence among people with type 1 diabetes. Given the similarity, this result can also be translated to other types of diabetes, such as people with type 2 diabetes. It is worth mentioning that apart from infection incidence, other factors such as emotional stress could also result in similar variable episodes of elevated blood glucose levels [17]. This can obviously impact the detection performance of the model. However, our results based on yearlong patients' data demonstrated that the use of carbohydrate consumption, insulin injections, and insulin-to-carbohydrate ratio along with the blood glucose could solve this confounding nature. Moreover, acute emotional stress, other than the chronic ones, might have less influence on one's meal appetite compared with infection incidence to skew the insulin-to-carbohydrate ratio [17].

\section{Relevance of the Data}

The informational values of the data, availability of the data, and cost of the data are the 3 key metrics necessary to evaluate the relevance of new surveillance data for a digital infectious disease detection system [58]. The informational value of the data assesses how informative the data are to facilitate the detection or characterization of infectious disease outbreaks. In this regard, the surveillance data must clearly indicate the absence or presence of infections either on an individual or population level or both in a timely manner. Furthermore, the rate of false alarms derived from the data is an important factor that dictates the acceptability of the surveillance data, which is in turn governed by the signal-to-noise ratio defining the signal's strength depicting the infection period as compared to the regular or normal period (baseline data) [58]. In this regard, our results demonstrated that the infection-induced signal exhibits high discriminative power from the baseline (normal or regular) patterns. The availability of surveillance data is another crucial indicator for screening potential types of data, which needs to be addressed [58]. In this regard, given the widespread and ubiquitous nature of mobile apps, and different sensors, people with type 1 diabetes collect far more data than ever. For example, many people with type 1 diabetes use continuous glucose monitors and insulin pumps, which are predicted to grow further in terms of both quality and quantity of data in the coming years. The most crucial challenge in this direction includes issues related to security, privacy, and confidentiality of user data if there is a necessity to collect user data into a central server than deploying the detection algorithm on the user's own mobile device. The cost of data delineates the associated cost in relation to acquiring the data in question, including the cost incurred for realizing the data collection system [58]. In this regard, the individual's self-recorded data are solely collected for their own use and used as a secondary source of information for disease surveillance purposes. Providing tailored and valuable feedback to the individual patient might further motivate them to participate on a large scale (for further details, see the section Ethical and Motivational Challenges).

\section{Framework of a Personalized Digital Infectious Disease Detection System}

Epidemic intelligence encompasses activities directed toward early detections, verification, and assessment of potential public health threats to notify and recommend necessary measures for the concerned bodies regarding the ongoing situation [56]. Early detection systems such as Google Flu Trends and other existing systems have certain limitations because they do not have the mechanisms to identify or track individual cases through diagnosis or screening based on a personalized health model. This limitation has a major impact and certainly introduces bias in disease outbreak prediction. Currently, a personalized health model, which resembles the way clinicians and epidemiologists classify an individual as normal, suspected, or confirmed case, for screening and case detection doesn't exist [58]. Having a personalized health model can provide information for both individual health-related decision support purposes and at the same time can be used for tracking infectious disease outbreaks among the public. The results of this study demonstrated that commencement of infection in people with type 1 diabetes significantly alters the individual blood glucose dynamics, and such a change can potentially be detected through modeling of the individual blood glucose dynamics. Moreover, incorporating various physiological parameters, for example, heart rate and body temperature, to a personalized health model will further enable the capture of infection incidence as early as possible, that is, incubation period. Therefore, the development of a personalized health model-based digital infectious disease detection system is vital for the success of next-generation public health surveillance systems. The data sources and signal exploited, outbreak detection algorithms employed, clustering approaches, and visualization techniques used to play a central role in any digital infectious disease detection systems by determining its accuracy (sensitivity) and timeliness (lead time) [56]. On the basis of the kind of data sources and signals exploited, infectious disease surveillance systems can be generally grouped into an indicator-based and event-based system [56,59,60]. Event-based systems mainly rely on 
unstructured data collected through formal or informal sources and is characterized by quick detection, reporting, and assessments of public health events, including clusters of disease $[56,60]$. On the other hand, indicator-based systems mainly use structured data, which are collected following a standard case definition and is characterized by routine reporting of disease cases $[56,60]$. The proposed system [26,61], as shown in Figure 14 , is categorized under event-based digital infectious disease detection systems, where the events are grouped under microevents and macroevents [56]. Under the umbrella of these events and the proposed system in general, a framework of several components such as infection detection algorithms (how to develop an algorithm to detect infection incidence at the individual level); clustering algorithms (how to group the infected individuals to form a cluster); visualization techniques (how to report and display the detected outbreak incidence) and further ethical and motivation challenges are briefly discussed below.

Figure 14. The Proposed System Architecture.

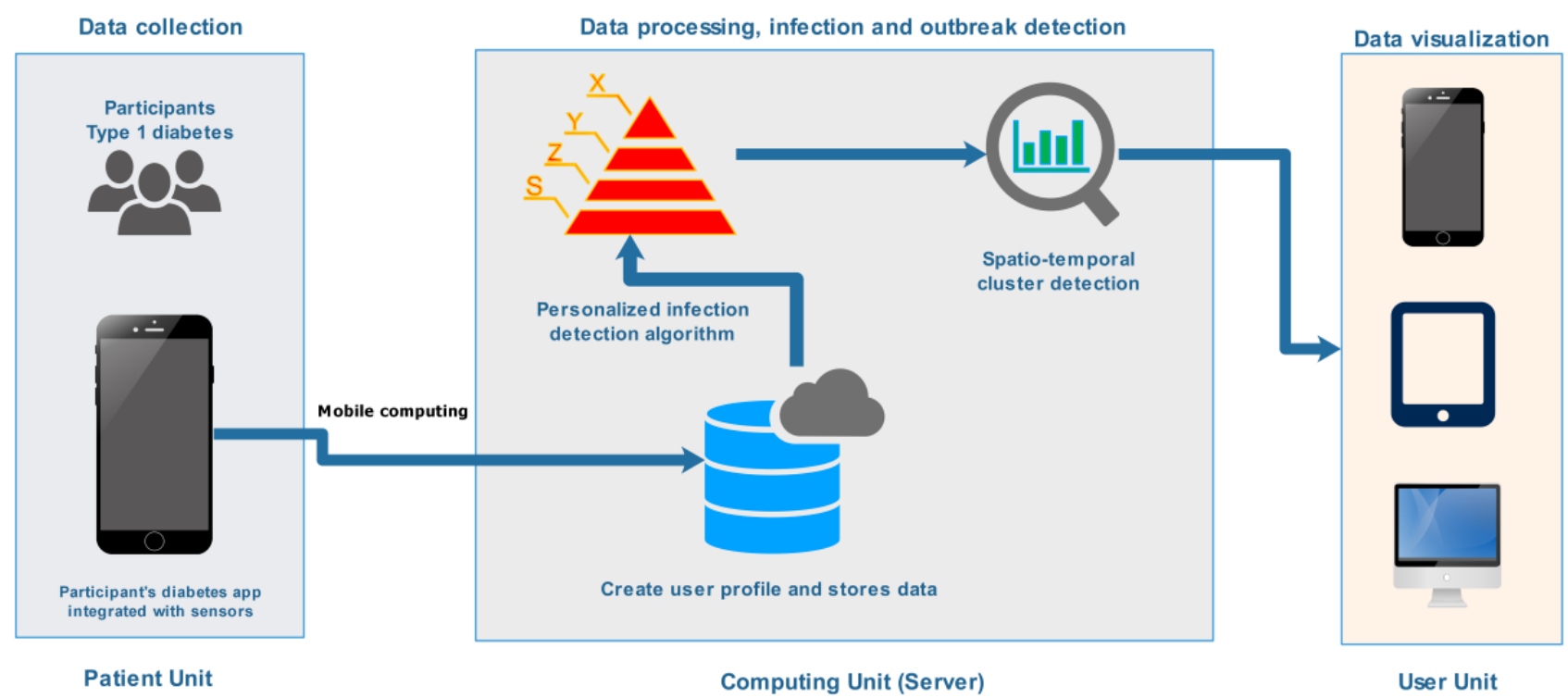

\section{Microevent: Individual-Level Detection of Infection Incidence}

The detection of microevents as the name suggests is carried out at an individual level by tracking the individual's diabetes profile including blood glucose levels, amount of insulin injections, carbohydrate consumption, physical activity or exercise sessions, and others. The presence of elevated blood glucose levels despite injecting higher amounts of insulin and consumption of less carbohydrates is regarded as a marker of an event of infection incidence and hence can be defined as a microevent for the event-based digital infectious disease detection system. Detecting the incidence of these kinds of deviation from the usual norm of blood glucose dynamics requires a proper personalized health model, which can learn from past history of the patient and judge whether the information conforms with the usual trend. Hence, the proposed personalized health model for detecting these types of microevents incorporates 3 components: a data source, personalized infection detection algorithm, and alarm management module, as shown in Figure 15. As can be seen from the figure, the personalized infection detection algorithm can be modeled using either a prediction model-based approach or a novelty or anomaly detection-based approach. 
Figure 15. The proposed personalized infection detection algorithms for detecting microevents (incidences of infections) in people with type 1 diabetes. These approaches are alternative means of achieving the same objective, which is detecting infection incidences.

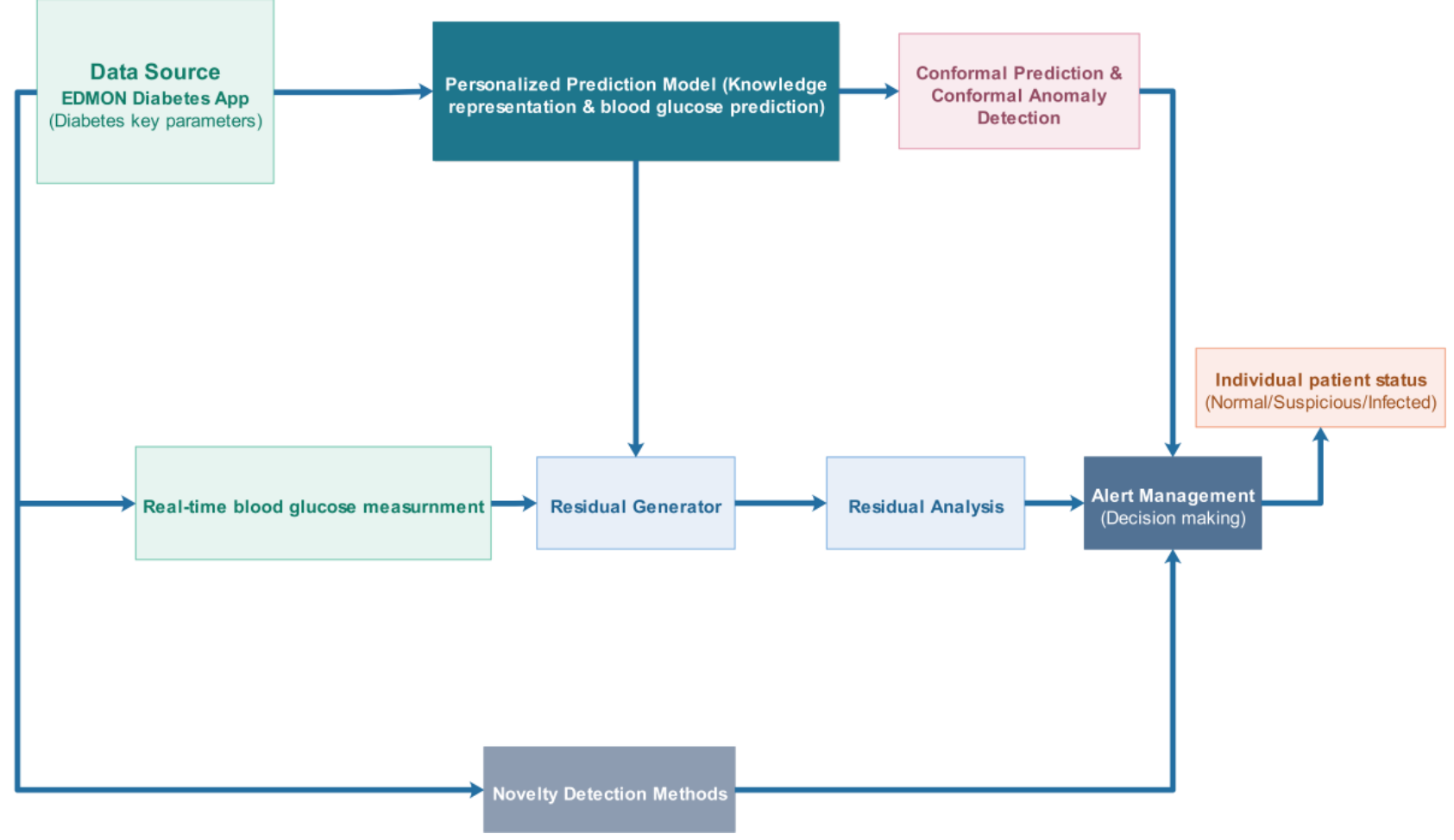

\section{Data Sources and Input}

The patient unit is a mobile health app, as shown in Figure 14, which integrates data from different sensors and wearables that record key diabetes parameters, such as blood glucose levels, insulin dosage, diet, physical activity, and other optional physiological parameters including body temperature, heart rate, blood pressure, and others [26,61]. The app is also expected to record the geographical location of the individual along with the time of data registration. For example, one way of estimating user location can be carried out based on global positioning system (GPS) information from the mobile phone during data registration [61]. The geographical location of the user can be the geographical coordinates of longitude and latitude [62], postal code address [63], or any local reference coordinates.

\section{Personalized Infection Detection Algorithm}

Detection of microevents can be carried out using individual self-recorded historical data based on a personalized health model, that is, either a prediction model $[64,65]$ or novelty detection algorithms [66-68], as shown in Figure 15. The prediction model-based algorithm requires learning the individual blood glucose dynamics for accurate prediction, and for the purpose of detecting the microevents, it can be implemented as either a residual-based [69-72] or a conformal prediction-based approach [73-80]. In a similar fashion, novelty detection-based algorithms can be other alternatives for detecting novel microevents relying on either supervised, semisupervised, and unsupervised approaches [4,66,67,81]. Different categories of novelty detection approaches could be exploited for detecting infection-induced deviations in blood glucose dynamics, including approaches based on statistical techniques [68], prediction, density [82-85], distance [67,86], classification or domain [4,62,63,87-92], clustering [62,93], and ensemble [67,68,80-82,85,86,92-95].

\section{Alarm Management (Decision Making)}

The alarm management module accepts the score computed by the personalized infection detection algorithm as input and evaluates the degree of severity of the infection incidence. The severity is evaluated based on the degree of abnormalities of the anomalies score, and a label could be assigned to the individual patient status as normal (0), suspicious ( -1$)$, and infected (1). For example, a rule-based fuzzy logic with membership functions of infected, normal, and suspicious can be used to assign the label indicating the severity of the infection incidence using the anomaly score. The output from the alarm management will be directly fed to the cluster detection analysis, which is used to detect a group of patients based on geography (space) and time so as to revel if there is any ongoing infectious disease outbreak.

\section{Macroevents: Population-Level Infectious Disease Outbreak Detection}

\section{Cluster Detection Mechanism}

Cluster detection is defined as the process of identifying a group of infected individuals with similar spatial, temporal, or spatio-temporal attributes [96]. A spatial cluster analysis only considers a patient's geographical location, and a temporal cluster analysis considers only the time aspect of the events. However, a spatio-temporal cluster analysis is conducted to look for aberrant patterns and detect a cluster of infected people within a specified geographical region and predefined timeframe $[96,97]$. The analysis of space time clusters is carried out based on a couple of steps: geocoding and identification, which transforms the patient address into meaningful coordinates and 
detecting the clusters based on the transformed location and time. A space time cluster analysis is the most favored approach when it comes to early detection of an infectious disease outbreak. A space time cluster analysis can be designed by performing a spatial analysis first and then superimposing the temporal aspect [97]. Regarding the proposed system, the input to the space time cluster detection analysis consists of the individual patient status from alarm management, user location, and time of data registration [26]. The status of the individual patient at any time can be normal (0), infected (1), or suspicious $(-1)$, which comes from alarm management. The user's geographical location can be geographical coordinates of longitude and latitude [98], postal code address [99], or any local reference coordinates. Estimation of user location can be carried out using GPS information from the user's mobile phone, which can be accessed during each data registration. The time aspects depend on the requirement of detection frequency and can be set to either an hourly or daily window. One optimal approach could be tracking the individual during each hour of the day for any statistically significant deviations and performing a concluding analysis at the end of each day based on the daily analysis. Various algorithms have been implemented in the literature, including the density-based clustering algorithm, Bayesian spatial scan statistics, K-NN with Haversian distance (K-nearness), cumulative summation, space time scan statistics, space time permutation scan statistic, and space scan statistics $[96,97,100]$, which can be further tested and adopted. The most important challenge is the sparsity of the data set considering the small proportion of people with type 1 diabetes that can be under surveillance over a large region. Therefore, it is necessary to adopt these cluster detection techniques to overcome data sparsity and produce acceptable detection accuracy. In the proposed system, the detected clusters, if there is any, can be displayed and viewed based on real-time and interactive data visualization tools.

\section{Data Visualization}

Data visualization is a mechanism by which detected clusters of disease outbreaks, if there is any, are presented to the responsible bodies for quicker public health actions and responses. Generally, such a visualization tool could report outbreaks of epidemic cases for investigation and follow-up, and it could also report the duration of the epidemic (timing), degree of severity of the epidemic, and the region under threat. In the literature, there are various implemented visualization tools and visual displays with regard to disease outbreak detection systems, including ArcGIS, Google map API, TwiInfo, OpenStreetMap, and JFreeChart, and display mechanisms such as maps, time series, graphs, and color indicators [96]. These visualization tools and display mechanisms can be further tested and adopted in the proposed system. The real-time health status of an individual from the ongoing tracking could be accessible to the end user and can be displayed in a stand-alone software app based on smartphones, tablets, and computers or a dedicated website [26]. Generally, both the data providers (participants) and the general population could benefit from the system in the sense that they can take actions needed to avoid being infected. Moreover, the individual patient could also receive analysis and feedback from the system to learn the situation, such as the degree and severity of deviation of different parameters, including blood glucose, insulin, diet, and insulin-to-carbohydrate ratio, along with their trend as compared with the noninfection period.

\section{Ethical and Motivational Challenges}

The implementation of a digital infectious disease detection system based on self-recorded data poses serious challenges that require special attention, such as user privacy and security, data confidentiality, user acceptance, and motivations [26,101], especially during data collection, transmission, and data storage $[102,103]$. Personal health-related data are sensitive, and the data collection, transmission, and data storage procedure need to follow the standards and regulations provided by the major governing bodies, such as General Data Protection Regulation (GDPR) and Health Insurance Portability and Accountability Act (HIPAA) [104,105]. This includes privacy-preserving mechanisms such as pseudonymization and anonymization to meet the necessary data compliance requirement along with user informed consent $[102,103]$. According to GDPR, the deidentification procedure is one of the recommended anonymization standards to preserve data confidentiality $[104,105]$. Moreover, from the technology perspective, it is necessary to look for a robust mechanism to ensure that user privacy and security are respected during data collection, transmission, and storage, as this is highly critical for successful acceptance of the proposed system [26,106]. One such alternative is to look for the possibility of deploying the infection detection algorithm (app logic) on the user (client) mobile device terminal to avoid transmission of patient data to a central server, where only the timely computed infection status of the patient will be sent to the central server for further cluster detection processing. However, this choice requires further feasibility studies to determine the cost, especially in terms of power constraints related to the mobile device terminal, since the detection algorithms need to continuously run in the background to compute the individual's infection status, at the most each hour of the day [26]. In addition, users might also lack willingness to adopt a new technology or system for various reasons ranging from lack of trust, lack of motivation, lack of perceived usefulness, and ease of use [26,101]. However, these challenges can be mitigated by properly buying user trust by developing state-of-the-art technology for preserving privacy, security, and confidentiality of the user and addressing factors that enhance user motivation, including usability knowledge, simplicity and ease of use, reduced time and frequency of interaction with the system, incentives, and others [101].

\section{Conclusions}

The relationship between infection incidents and elevated blood glucose levels has been known for a long time. People with type 1 diabetes often experience prolonged episodes of elevated blood glucose levels as a result of infection incidence. Despite the fact that patients increasingly gather data about themselves, there are no solid findings on how to use such self-recorded data as a secondary source of information for other purposes, such as self-management-related decision support during infection incidence and digital infectious disease detection systems. We presented the effect of infection incidence on key 
parameters of the blood glucose dynamics along with the necessary framework to exploit the information for realizing a digital infectious disease detection system and further shed light on the possibility of assisting individuals during infection-related blood glucose management crises. The results demonstrated that despite tight blood glucose control, blood glucose level is still elevated during infection incidence. The analysis shows that infection incidences have a significant impact on blood glucose dynamics as compared with the other patient-uncontrollable factors. All of these findings indicate that blood glucose levels were elevated despite a higher amount of insulin injection and reduced carbohydrate consumption, which are quite significant changes that could possibly be detected through personalized modeling that spans from prediction models to anomaly detection algorithms. However, further large-scale studies are required to strengthen the findings. Moreover, future research should investigate the possibility of improving detection time and disease characterization. Early detection, that is, during the incubation period, is a critical component of any outbreak detection system and therefore needs to be improved by analyzing how various features of CGM can be used in context with other parameters, such as diet, insulin, and physical activity data. For instance, different individuals with type 1 diabetes often reported the experiences of an elevated episode of blood glucose levels before the onset of the first symptoms. Disease characterization involves determining the type and nature of pathogens that cause the infection, which is an important component of outbreak reporting. The extent and degree of the impact of infection incidence on blood glucose dynamics are highly correlated with the disease pathogens involved. In this regard, carefully analyzing a large-scale self-recorded data set containing several infection incidences (different pathogens) could characterize them based on their effect on blood glucose dynamics. Generally, we foresee that these findings can benefit the efforts toward building next-generation digital infectious disease surveillance systems and provoke further thoughts in this challenging field.

\section{Acknowledgments}

The work presented in this paper is part of the project "Electronic Disease Surveillance Monitoring Network (EDMON) system," which is funded by the University of Troms $\varnothing$ - The Arctic University of Norway and National Library of Medicine "Mechanistic machine learning" (grant number: LM012734) and is the PhD program of the first author, AW. The authors would like to extend their sincere gratitude to all the participants of the study.

\section{Authors' Contributions}

The first author, AW, conceived the study, designed and performed the experiments, and wrote the manuscript. IK, EÅ, AH, DA, and GH provided successive inputs and revised the manuscript. All authors approved the final manuscript.

\section{Conflicts of Interest}

None declared.

\section{Multimedia Appendix 1}

Comparative analysis of parameters of blood glucose dynamics with and without infection incidences.

[DOCX File, 9296 KB-Multimedia Appendix 1]

\section{Multimedia Appendix 2}

Analytical plot of the normal/regular patient years.

[DOCX File, 1346 KB-Multimedia Appendix 2]

\section{Multimedia Appendix 3}

Analytical plot of the patient years with acute infection.

[DOCX File, 1662 KB-Multimedia Appendix 3]

\section{References}

1. Choi J, Cho Y, Shim E, Woo H. Web-based infectious disease surveillance systems and public health perspectives: a systematic review. BMC Public Health 2016 Dec 8;16(1):1238 [FREE Full text] [doi: 10.1186/s12889-016-3893-0] [Medline: 27931204]

2. Hope K, Durrheim DN, d'Espaignet ET, Dalton C. Syndromic Surveillance: is it a useful tool for local outbreak detection? J Epidemiol Community Health 2006 May;60(5):374-375 [FREE Full text] [doi: 10.1136/jech.2005.035337] [Medline: 16680907]

3. Banaee H, Ahmed MU, Loutfi A. Data mining for wearable sensors in health monitoring systems: a review of recent trends and challenges. Sensors (Basel) 2013 Dec 17;13(12):17472-17500 [FREE Full text] [doi: 10.3390/s131217472] [Medline: 24351646] 
4. Woldaregay AZ, Årsand E, Botsis T, Albers D, Mamykina L, Hartvigsen G. Data-driven blood glucose pattern classification and anomalies detection: machine-learning applications in type 1 diabetes. J Med Internet Res 2019 May 1;21(5):e11030 [FREE Full text] [doi: $\underline{10.2196 / 11030}$ ] [Medline: $\underline{\text { 31042157] }}$

5. Fawcett T. Mining the quantified self: personal knowledge discovery as a challenge for data science. Big Data 2015 Dec;3(4):249-266. [doi: 10.1089/big.2015.0049] [Medline: 27441406]

6. Gurrin C, Smeaton AF, Doherty AR. LifeLogging: personal big data. FNT Inf Ret 2014;8(1):1-125 [FREE Full text] [doi: 10.1561/1500000033]

7. Prince JD. The quantified self: operationalizing the quotidien. J Electron Resour Med Libr 2014 May 30;11(2):91-99 [FREE Full text] [doi: 10.1080/15424065.2014.909145]

8. Rawassizadeh R, Momeni E, Dobbins C, Mirza-Babaei P, Rahnamoun R. Lesson learned from collecting quantified self information via mobile and wearable devices. J Sens Actuator Netw 2015 Nov 5;4(4):315-335 [FREE Full text] [doi: 10.3390/jsan4040315]

9. Bellazzi R, Abu-Hanna A. Data mining technologies for blood glucose and diabetes management. J Diabetes Sci Technol 2009 May 1;3(3):603-612 [FREE Full text] [doi: 10.1177/193229680900300326] [Medline: 20144300]

10. Rodríguez-Rodríguez I, Rodríguez JV, Zamora-Izquierdo M. Variables to be monitored via biomedical sensors for complete type 1 diabetes mellitus management: an extension of the 'on-board' concept. J Diabetes Res 2018;2018:4826984 [FREE Full text] [doi: 10.1155/2018/4826984] [Medline: $\underline{30363935]}$

11. Vayena E, Salathé M, Madoff LC, Brownstein JS. Ethical challenges of big data in public health. PLoS Comput Biol 2015 Feb;11(2):e1003904 [FREE Full text] [doi: 10.1371/journal.pcbi.1003904] [Medline: 25664461]

12. Denecke K. An ethical assessment model for digital disease detection technologies. Life Sci Soc Policy 2017 Sep 20;13(1):16 [FREE Full text] [doi: 10.1186/s40504-017-0062-x] [Medline: 28929347]

13. Tsui F, Espino JU, Dato VM, Gesteland PH, Hutman J, Wagner MM. Technical description of RODS: a real-time public health surveillance system. J Am Med Inform Assoc 2003;10(5):399-408 [FREE Full text] [doi: 10.1197/jamia.M1345] [Medline: $\underline{12807803}$ ]

14. Ogurtsova K, da Rocha Fernandes J, Huang Y, Linnenkamp U, Guariguata L, Cho N, et al. IDF diabetes atlas: global estimates for the prevalence of diabetes for 2015 and 2040. Diabetes Res Clin Pract 2017 Jun;128:40-50. [doi: 10.1016/j.diabres.2017.03.024] [Medline: 28437734]

15. Clark M. What is diabetes? In: Ogden J, editor. Understanding Diabetes. New Jersey, United States: John Wiley \& Sons Ltd; 2004.

16. Bazaev NA, Pletenev AN, Pozhar KV. Classification of factors affecting blood glucose concentration dynamics. Biomed Eng 2013 Jul 18;47(2):100-103. [doi: 10.1007/s10527-013-9344-7] [Medline: 23789157]

17. Finan DA, Zisser H, Jovanovič L, Bevier WC, Seborg DE. Automatic detection of stress states in type 1 diabetes subjects in ambulatory conditions. Ind Eng Chem Res 2010 Sep 1;49(17):7843-7848 [FREE Full text] [doi: 10.1021/ie901891c] [Medline: 20953334]

18. Botsis T, Hejlesen O, Bellika JG, Hartvigsen G. Electronic disease surveillance for sensitive population groups - the diabetics case study. Stud Health Technol Inform 2008;136:365-370. [Medline: 18487758]

19. Rayfield EJ, Ault MJ, Keusch GT, Brothers MJ, Nechemias C, Smith H. Infection and diabetes: the case for glucose control. Am J Med 1982 Mar;72(3):439-450. [doi: 10.1016/0002-9343(82)90511-3] [Medline: 7036735]

20. Simonsen JR, Harjutsalo V, Järvinen A, Kirveskari J, Forsblom C, Groop P, FinnDiane Study Group. Bacterial infections in patients with type 1 diabetes: a 14-year follow-up study. BMJ Open Diabetes Res Care 2015;3(1):e000067 [FREE Full text] [doi: 10.1136/bmjdrc-2014-000067] [Medline: 25767718]

21. Yki-Järvinen H, Sammalkorpi K, Koivisto VA, Nikkilä EA. Severity, duration, and mechanisms of insulin resistance during acute infections. J Clin Endocrinol Metab 1989 Aug;69(2):317-323. [doi: 10.1210/jcem-69-2-317] [Medline: 2666428]

22. Botsis T, Lai AM, Hripcsak G, Palmas W, Starren JB, Hartvigsen G. Proof of concept for the role of glycemic control in the early detection of infections in diabetics. Health Informatics J 2012 Mar;18(1):26-35. [doi: 10.1177/1460458211428427] [Medline: 22447875]

23. Botsis T, Hartvigsen G. Exploring new directions in disease surveillance for people with diabetes: lessons learned and future plans. Stud Health Technol Inform 2010;160(Pt 1):466-470. [Medline: 20841730]

24. Arsand E, Walseth OA, Andersson N, Fernando R, Granberg O, Bellika JG, et al. Using blood glucose data as an indicator for epidemic disease outbreaks. Stud Health Technol Inform 2005;116:217-222. [Medline: 16160262]

25. Granberg O, Bellika JG, Arsand E, Hartvigsen G. Automatic infection detection system. Stud Health Technol Inform 2007;129(Pt 1):566-570. [Medline: 17911780]

26. Woldaregay AZ, Årsand E, Giordanengo A, Albers D, Mamykina L, Botsis T, et al. EDMON-A Wireless Communication Platform for a Real-Time Infectious Disease Outbreak Detection System Using Self-Recorded Data from People with Type 1 Diabetes. In: The 15th Scandinavian Conference on Health Informatics. 2017 Presented at: CHI'17; August 29, 2017; Kristiansand, Norway URL: https://ep.liu.se/konferensartikel.aspx?series=ecp\&issue=145\&Article No=3

27. Lauritzen JN, Årsand E, Vuurden KV, Bellika JG, Hejlesen OK, Hartvigsen G. Towards a Mobile Solution for Predicting Illness in Type 1 Diabetes Mellitus: Development of a Prediction Model for Detecting Risk of Illness in Type 1 Diabetes Prior to Symptom Onset. In: 2nd International Conference on Wireless Communication, Vehicular Technology, Information 
Theory and Aerospace \& Electronic Systems Technology. 2011 Presented at: Wireless VITAE; February 28-March 3, 2011; Chennai, India. [doi: 10.1109/wirelessvitae.2011.5940877]

28. Skrøvseth SO, Bellika JG, Godtliebsen F. Causality in scale space as an approach to change detection. PLoS One 2012;7(12):e52253 [FREE Full text] [doi: 10.1371/journal.pone.0052253] [Medline: 23300626]

29. Botsis T, Bellika JG, Hartvigsen G. Disease Surveillance Systems for Sensitive Population Groups. Faculty \& Staff Insider - University of Washington. 2007. URL: https://faculty.washington.edu/lober/www.isdsjournal.org/htdocs/articles/2026. pdf [accessed 2020-07-23]

30. Botsis T, Hejlesen O, Bellika JG, Hartvigsen G. Blood Glucose Levels as an Indicator for the Early Detection of Infections In Type-1 Diabetics. Faculty \& Staff Insider - University of Washington. 2007. URL: http://faculty.washington.edu/lober/ www.isdsjournal.org/htdocs/articles/2025.pdf [accessed 2020-07-23]

31. Lauritzen J, Årsand E, Van Vuurden K, Hejlesen O, Hartvigsen G. Exploring illness prediction in Type 1 Diabetes Mellitus Pre-Symptom Onset. E-health Research. 2010. URL: https://ehealthresearch.no/en/publications/ exploring-illness-prediction-in-type-1-diabetes-mellitus-pre-symptom-onset-1 [accessed 2020-07-23]

32. Hartvigsen G, Årsand E, Botsis T, van Vuurden K, Johansen M, Bellika JG. Reusing patient data to enhance patient empowerment and electronic disease surveillance. J Inf Technol 2009;7(1):4-12.

33. Botsis T, Bellika JG, Hartvigsen G. New Directions in Electronic Disease Surveillance: Detection of Infectious Diseases during the Incubation Period. In: International Conference on eHealth. 2009 Presented at: EH'09; February 1-7, 2009; Cancun, Mexico p. 176-183. [doi: 10.1109/etelemed.2009.9]

34. Botsis T, Hejlesen O, Bellika JG, Hartvigsen G. Blood Glucose Levels as a Censor for Early Detection of Infection in Type-1 Diabetics. Faculty \& Staff Insider - University of Washington. 2007. URL: http://faculty.washington.edu/lober/ www.isdsjournal.org/htdocs/articles/2025.pdf [accessed 2020-07-23]

35. Botsis T, Hejlesen O, Bellika JG, Hartvigsen G. Disease surveillance systems for diabetics. In: Telemedicine and e-Health. 2008 Mar Presented at: The American Telemedicine Association Annual International Meeting and Exposition; 2008; Seattle p. 108-108. [doi: 10.1089/tmj.2008.9983.supp]

36. Botsis T, Hejlesen O, Bellika JG, Hartvigsen G. Electronic infectious disease surveillance systems for diabetics. 2008 Presented at: International Conference on Advanced Technologies \& Treatments for Diabetes; Prague, Czech Republic.

37. Brealey D, Singer M. Hyperglycemia in critical illness: a review. J Diabetes Sci Technol 2009 Nov 1;3(6):1250-1260 [FREE Full text] [doi: 10.1177/193229680900300604] [Medline: 20144378]

38. Marik PE, Bellomo R. Stress hyperglycemia: an essential survival response!. Crit Care 2013 Mar 6;17(2):305 [FREE Full text] [doi: 10.1186/cc12514] [Medline: 23470218]

39. Årsand E, Muzny M, Bradway M, Muzik J, Hartvigsen G. Performance of the first combined smartwatch and smartphone diabetes diary application study. J Diabetes Sci Technol 2015 May;9(3):556-563 [FREE Full text] [doi: 10.1177/1932296814567708] [Medline: 25591859]

40. Features. Spike App. URL: https://spike-app.com/\#features1 [accessed 2019-09-20]

41. Gillespie SJ, Kulkarni KD, Daly AE. Using carbohydrate counting in diabetes clinical practice. J Am Diet Assoc 1998 Aug;98(8):897-905. [doi: 10.1016/S0002-8223(98)00206-5] [Medline: 9710660]

42. Rasoulzadeh V, Erkus EC, Yogurt TA, Ulusoy I, Zergeroğlu SA. A comparative stationarity analysis of EEG signals. Ann Oper Res 2016 Apr 26;258(1):133-157 [FREE Full text] [doi: 10.1007/s10479-016-2187-3]

43. Azami H, Mohammadi K, Bozorgtabar B. An improved signal segmentation using moving average and Savitzky-Golay filter. J Signal Inf Process 2012;03(01):39-44. [doi: 10.4236/jsip.2012.31006]

44. Botev ZI, Grotowski JF, Kroese DP. Kernel density estimation via diffusion. Ann Statist 2010 Oct;38(5):2916-2957. [doi: $\underline{10.1214 / 10-\operatorname{aos} 799]}$

45. Gramacki A. Nonparametric density estimation. In: Nonparametric Kernel Density Estimation and Its Computational Aspects. Cham, Switzerland: Springer International Publishing; 2018:7-24.

46. Gramacki A. Bandwidth selectors for kernel density estimation. In: Nonparametric Kernel Density Estimation and Its Computational Aspects. Cham, Switzerland: Springer International Publishing; 2018:63-83.

47. Heidenreich N, Schindler A, Sperlich S. Bandwidth selection for kernel density estimation: a review of fully automatic selectors. AStA Adv Stat Anal 2013 Jun 2;97(4):403-433 [FREE Full text] [doi: 10.1007/s10182-013-0216-y]

48. Gramacki A. Kernel density estimation. In: Nonparametric Kernel Density Estimation and Its Computational Aspects. Cham, Switzerland: Springer International Publishing; 2018:25-62.

49. Zdravko B. Kernel Density Estimator. MathWorks. 2015. URL: https://www.mathworks.com/matlabcentral/fileexchange/ 14034-kernel-density-estimator [accessed 2019-06-22]

50. Rossini AJ. 'Applied smoothing techniques for data analysis: the kernel approach with s-plus illustrations' by Adrian W Bowman and Adelchi Azzalini. Comput Stat 2000 Sep 11;15(2):301-302 [FREE Full text] [doi: 10.1007/s001800000033]

51. Bowman AW, Azzalini A. Applied Smoothing Techniques for Data Analysis: The Kernel Approach With S-Plus Illustrations. Oxford, UK: OUP Oxford; 1997.

52. Yi C. Bivariant Kernel Density Estimation (V2.1). MathWorks. 2013. URL: https://la.mathworks.com/matlabcentral/ fileexchange/19280-bivariant-kernel-density-estimation-v2-1?s_tid=prof_contriblnk [accessed 2019-06-22] 
53. Yamaguchi M, Kaseda C, Yamazaki K, Kobayashi M. Prediction of blood glucose level of type 1 diabetics using response surface methodology and data mining. Med Biol Eng Comput 2006 Jun;44(6):451-457. [doi: 10.1007/s11517-006-0049-x] [Medline: $\underline{16937196]}$

54. van Herpe T, Pluymers B, Espinoza M, van den Berghe G, de Moor BA. A minimal model for glycemia control in critically ill patients. Conf Proc IEEE Eng Med Biol Soc 2006;2006:5432-5435 [FREE Full text] [doi: 10.1109/IEMBS.2006.260613] [Medline: 17946700$]$

55. Waldhäusl WK, Bratusch-Marrain P, Komjati M, Breitenecker F, Troch I. Blood glucose response to stress hormone exposure in healthy man and insulin dependent diabetic patients: prediction by computer modeling. IEEE Trans Biomed Eng 1992 Aug;39(8):779-790 [FREE Full text] [doi: 10.1109/10.148386] [Medline: 1354649]

56. O'Shea J. Digital disease detection: a systematic review of event-based internet biosurveillance systems. Int J Med Inform 2017 May;101:15-22 [FREE Full text] [doi: 10.1016/j.ijmedinf.2017.01.019] [Medline: 28347443]

57. Mizock BA. Alterations in carbohydrate metabolism during stress: a review of the literature. Am J Med 1995 Jan;98(1):75-84 [FREE Full text] [doi: 10.1016/S0002-9343(99)80083-7] [Medline: 7825623]

58. Wagner MM, Moore AW, Aryel RM, editors. Handbook of Biosurveillance. New York, USA: Elsevier; 2006.

59. Event-Based Surveillance. Centers for Disease Control and Prevention. URL: https://www.cdc.gov/globalhealth/ healthprotection/gddopscenter/how.html [accessed 2019-06-26]

60. World Health Organization. A Guide to Establishing Event-Based Surveillance. Geneva, Switzerland: World Health Organization; 2008.

61. Coucheron S, Woldaregay AZ, Årsand E, Botsis T, Hartvigsen G. EDMON - A System Architecture for Real-Time Infection Monitoring and Outbreak Detection Based on Self-Recorded Data from People with Type 1 Diabetes: System Design and Prototype Implementation. In: The 17th Scandinavian Conference on Health Informatics. 2019 Presented at: CHI'19; November 12, 2019; Oslo, Norway p. 37-44 URL: https://ep.liu.se/ecp/161/007/ecp19161007.pdf

62. Tax DM. One-Class Classification: Concept Learning in the Absence of Counter-Examples. South Holland, Netherlands: Technische Universiteit Delft; 2002.

63. Mazhelis O. One-class classifiers: a review and analysis of suitability in the context of mobile-masquerader detection. S Afr Comput J 2006;36:29-48 [FREE Full text]

64. Oviedo S, Vehí J, Calm R, Armengol J. A review of personalized blood glucose prediction strategies for T1DM patients. Int J Numer Method Biomed Eng 2017 Jun;33(6):---. [doi: 10.1002/cnm.2833] [Medline: 27644067]

65. Woldaregay AZ, Årsand E, Walderhaug S, Albers D, Mamykina L, Botsis T, et al. Data-driven modeling and prediction of blood glucose dynamics: machine learning applications in type 1 diabetes. Artif Intell Med 2019 Jul;98:109-134 [FREE Full text] [doi: 10.1016/j.artmed.2019.07.007] [Medline: 31383477]

66. Dunning T, Friedman E. In: Loukides M, editor. Practical Machine Learning: A New Look at Anomaly Detection. New York, USA: O'Reilly Media Inc; 2018.

67. Chandola V, Banerjee A, Kumar V. Anomaly detection: A survey. ACM Comput Surv 2009 Jul;41(3):1-58 [FREE Full text] [doi: $\underline{10.1145 / 1541880.1541882]}$

68. Pimentel MA, Clifton DA, Clifton L, Tarassenko L. A review of novelty detection. Sig Process 2014 Jun;99:215-249 [FREE Full text] [doi: 10.1016/j.sigpro.2013.12.026]

69. Haslett J, Haslett SJ. The three basic types of residuals for a linear model. Int Statistical Rev 2007 Apr;75(1):1-24 [FREE Full text] [doi: 10.1111/j.1751-5823.2006.00001.x]

70. Harvey AC, Koopman SJ. Diagnostic checking of unobserved-components time series models. J Bus Econ Stat 1992 Oct;10(4):377-389. [doi: 10.1080/07350015.1992.10509913]

71. Yu Y, Zhu Y, Li S, Wan D. Time series outlier detection based on sliding window prediction. Math Probl Eng 2014;2014:1-14 [FREE Full text] [doi: 10.1155/2014/879736]

72. Woldaregay AZ, Årsand E, Botsis T, Hartvigsen G. An early infectious disease outbreak detection mechanism based on self-recorded data from people with diabetes. Stud Health Technol Inform 2017;245:619-623. [Medline: 29295170]

73. Vovk V, Gammerman A, Shafer G. Conformal prediction. In: Algorithmic Learning in a Random World. Boston, MA: Springer US; 2005:17-51.

74. Vovk V. The basic conformal prediction framework. In: Conformal Prediction for Reliable Machine Learning. New York, USA: Morgan Kaufmann; 2014:3-19.

75. Vovk V. Beyond the basic conformal prediction framework. In: Conformal Prediction for Reliable Machine Learning. New York, USA: Morgan Kaufmann; 2014:21-46.

76. James S. The Efficiency of Conformal Predictors for Anomaly Detection. Royal Holloway, University of London: Research. 2016. URL: https://pure.royalholloway.ac.uk/portal/en/publications/ the-efficiency-of-conformal-predictors-for-anomaly-detection(d68cdec7-7d84-414b-9498-0c8539bb57b8)/export.html [accessed 2020-07-23]

77. Laxhammar R, Falkman G. Inductive conformal anomaly detection for sequential detection of anomalous sub-trajectories. Ann Math Artif Intell 2013 Sep 20;74(1-2):67-94 [FREE Full text] [doi: 10.1007/s10472-013-9381-7]

78. Shafer G, Vovk V. A tutorial on conformal prediction. J Mach Learn Res 2008 Jun 1;9(-):371-421 [FREE Full text] [doi: 10.5555/1390681.1390693] 
79. Smith J, Nouretdinov I, Craddock R, Offer C, Gammerman A. Anomaly Detection of Trajectories with Kernel Density Estimation by Conformal Prediction. In: IFIP International Conference on Artificial Intelligence Applications and Innovations. 2014 Presented at: AIAI'14; September 19-21, 2014; Rhodos, Greece URL: https://doi.org/10.1007/978-3-662-44722-2 29 [doi: 10.1007/978-3-662-44722-2_29]

80. Laxhammar R. Conformal Anomaly Detection: Detecting Abnormal Trajectories in Surveillance Applications. Skövde: School of Informatics, University of Skövde; 2014.

81. Mehrotra K, Mohan CK, Huang H. Anomaly Detection Principles and Algorithms. New York, USA: Springer; 2017.

82. Zhao Z, Mehrotra KG, Mohan CK. Ensemble Algorithms for Unsupervised Anomaly Detection. In: International Conference on Industrial, Engineering and Other Applications of Applied Intelligent Systems. 2015 Presented at: IEA/AIE'15; June 10-12, 2015; Seoul, Korea (Republic of) URL: https://link.springer.com/content/pdf/10.1007\%2F978-3-319-19066-2.pdf [doi: 10.1007/978-3-319-19066-2 50]

83. Breunig MM, Kriegel HP, Ng RT, Sanders J. LOF: Identifying Density-Based Local Outliers. In: Proceedings of the 2000 ACM SIGMOD International Conference on Management of Data. 2000 Presented at: SIGMOD'00; May 16-18, 2000; Dallas, Texas, USA. [doi: 10.1145/342009.335388]

84. Tang J, Chen Z, Fu AW, Cheung DW. Enhancing Effectiveness of Outlier Detections for Low Density Patterns. In: Pacific-Asia Conference on Knowledge Discovery and Data Mining. 2002 Presented at: PAKDD'02; May 6-8, 2002; Taipei, Taiwan. [doi: 10.1007/3-540-47887-6 53]

85. Nguyen HV, Nguyen TT, Nguyen QU. Sequential Ensemble Method for Unsupervised Anomaly Detection. In: 9th International Conference on Knowledge and Systems Engineering (KSE). 2017 Presented at: KSE'17; October 19-21, 2017; Hue, Vietnam. [doi: 10.1109/kse.2017.8119437]

86. Goldstein M, Uchida S. A comparative evaluation of unsupervised anomaly detection algorithms for multivariate data. PLoS One 2016;11(4):e0152173 [FREE Full text] [doi: 10.1371/journal.pone.0152173] [Medline: 27093601]

87. Irigoien I, Sierra B, Arenas C. Towards application of one-class classification methods to medical data. ScientificWorldJournal 2014;2014:730712 [FREE Full text] [doi: 10.1155/2014/730712] [Medline: 24778600]

88. Tax DM, Duin RP. Support vector data description. Mach Learn 2004 Jan;54(1):45-66 [FREE Full text] [doi: 10.1023/b:mach.0000008084.60811.49]

89. Schölkopf B, Williamson RC, Smola AJ, Shawe-Taylor J, Platt JC. Support Vector Method for Novelty Detection. In: The 12th International Conference on Neural Information Processing. 1999 Presented at: NIPS'99; November 29-December 4, 1999; Denver, Colorado, USA URL: https://dl.acm.org/doi/10.5555/3009657.3009740 [doi: 10.5555/3009657.3009740]

90. Juszczak P, Tax DM, Pe kalska E, Duin RP. Minimum spanning tree based one-class classifier. Neurocomputing 2009 Mar;72(7-9):1859-1869 [FREE Full text] [doi: 10.1016/j.neucom.2008.05.003]

91. Khan SS, Madden MG. One-class classification: taxonomy of study and review of techniques. Knowl Eng Rev 2014 Jan 24;29(3):345-374 [FREE Full text] [doi: 10.1017/s026988891300043x]

92. Wang B, Mao Z. One-class classifiers ensemble based anomaly detection scheme for process control systems. T I Meas Control 2017 Sep 21;40(12):3466-3476 [FREE Full text] [doi: 10.1177/0142331217724508]

93. Ahmad S, Lavin A, Purdy S, Agha Z. Unsupervised real-time anomaly detection for streaming data. Neurocomputing 2017 Nov;262:134-147 [FREE Full text] [doi: 10.1016/j.neucom.2017.04.070]

94. Yu E, Parekh P. A bayesian ensemble for unsupervised anomaly detection. arXiv 2016:- preprint [FREE Full text]

95. Shoemaker L, Hall LO. Anomaly Detection Using Ensembles. In: International Workshop on Multiple Classifier Systems. 2011 Presented at: MCS'11; June 15-17, 2011; Naples, Italy URL: https://doi.org/10.1007/978-3-642-21557-5_3 [doi: $10.1007 / 978-3-642-21557-5 \quad 3]$

96. Yeng PK, Woldaregay AZ, Solvoll T, Hartvigsen G. Cluster detection mechanisms for syndromic surveillance systems: systematic review and framework development. JMIR Public Health Surveill 2020 May 26;6(2):e11512 [FREE Full text] [doi: 10.2196/11512] [Medline: $\underline{32357126]}$

97. Shi Z, Pun-Cheng L. Spatiotemporal data clustering: a survey of methods. Int J Geogr Inf Sci 2019 Feb 28;8(3):112 [FREE Full text] [doi: 10.3390/ijgi8030112]

98. Duangchaemkarn K, Chaovatut V, Wiwatanadate P, Boonchieng E. Symptom-based data preprocessing for the detection of disease outbreak. Conf Proc IEEE Eng Med Biol Soc 2017 Jul;2017:2614-2617 [FREE Full text] [doi: 10.1109/EMBC.2017.8037393] [Medline: 29060435]

99. Grubesic TH, Matisziw TC. On the use of ZIP codes and ZIP code tabulation areas (ZCTAs) for the spatial analysis of epidemiological data. Int J Health Geogr 2006 Dec 13;5:58 [FREE Full text] [doi: 10.1186/1476-072X-5-58] [Medline: 17166283]

100. Glatman-Freedman A, Kaufman Z, Kopel E, Bassal R, Taran D, Valinsky L, et al. Near real-time space-time cluster analysis for detection of enteric disease outbreaks in a community setting. J Infect 2016 Aug;73(2):99-106. [doi: 10.1016/j.jinf.2016.04.038] [Medline: 27311747]

101. Woldaregay AZ, Issom D, Henriksen A, Marttila H, Mikalsen M, Pfuhl G, et al. Motivational factors for user engagement with mhealth apps. Stud Health Technol Inform 2018;249:151-157. [Medline: 29866972] 
102. Klingler C, Silva DS, Schuermann C, Reis AA, Saxena A, Strech D. Ethical issues in public health surveillance: a systematic qualitative review. BMC Public Health 2017 Apr 4;17(1):295 [FREE Full text] [doi: 10.1186/s12889-017-4200-4] [Medline: 28376752]

103. Geneviève LD, Martani A, Wangmo T, Paolotti D, Koppeschaar C, Kjelsø C, et al. Participatory disease surveillance systems: ethical framework. J Med Internet Res 2019 May 23;21(5):e12273 [FREE Full text] [doi: 10.2196/12273] [Medline: $\underline{31124466]}$

104. Rumbold JM, Pierscionek B. The effect of the general data protection regulation on medical research. J Med Internet Res 2017 Feb 24;19(2):e47 [FREE Full text] [doi: 10.2196/jmir.7108] [Medline: 28235748]

105. Hintze M. Viewing the GDPR through a de-identification lens: a tool for compliance, clarification, and consistency. Int Data Priv Law 2017;8(1):86-101 [FREE Full text] [doi: 10.1093/idpl/ipx020]

106. Sun W, Cai Z, Li Y, Liu F, Fang S, Wang G. Security and privacy in the medical internet of things: a review. Secur Commun Netw 2018;2018:1-9 [FREE Full text] [doi: 10.1155/2018/5978636]

\section{Abbreviations}

CGM: continuous glucose monitoring

CRH: counterregulatory hormone

GDPR: General Data Protection Regulation

GPS: global positioning system

IoT: Internet of Things

SMBG: self-monitoring of blood glucose

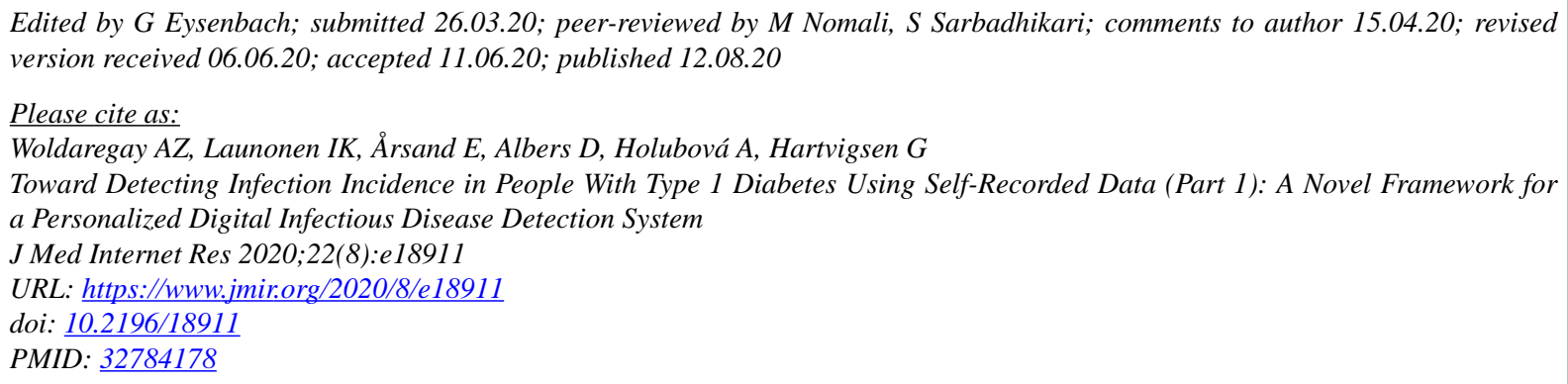

(C)Ashenafi Zebene Woldaregay, Ilkka Kalervo Launonen, Eirik Årsand, David Albers, Anna Holubová, Gunnar Hartvigsen. Originally published in the Journal of Medical Internet Research (http://www.jmir.org), 12.08.2020. This is an open-access article distributed under the terms of the Creative Commons Attribution License (https://creativecommons.org/licenses/by/4.0/), which permits unrestricted use, distribution, and reproduction in any medium, provided the original work, first published in the Journal of Medical Internet Research, is properly cited. The complete bibliographic information, a link to the original publication on http://www.jmir.org/, as well as this copyright and license information must be included. 